\title{
LA SANTA SEDE, LA REPÚBLICA Y LOS NIÑOS VASCOS: UNA BATALLA DIPLOMÁTICA DENTRO DE LA GUERRA CIVIL ESPAÑOLA*
}

\author{
POR \\ AnTón M. Pazos \\ Consejo Superior de Investigaciones Científicas \\ Instituto de Estudios Gallegos «Padre Sarmiento»
}

\section{RESUMEN}

Con la llegada a la España nacional de Ildebrando Antoniutti, enviado por la Santa Sede con la aparente misión humanitaria de ayudar a repatriar a los niños vascos exiliados en 1937, se abrió un período de acercamiento diplomático, pero también se puso en marcha lo que justificaba su presencia en España: repatriar a los niños. Se analizan aquí distintos aspectos de lo que fue una verdadera batalla diplomática, con niños de fondo, a partir de documentación del Archivo Gomá, del archivo del Ministerio de Asuntos Exteriores - franquista y republicano- y del Archivo Secreto Vaticano. El artículo anticipa una próxima monografía sobre el papel de la Santa Sede en la repatriación de los niños durante la guerra civil española.

Palabas ClaVe: Ildebrando Antoniutti, Franco, Santa Sede. República, Guerra civil Española, Niños vascos, Exilio, Inglaterra, Bélgica, Francia, Van Roey, 1936-1939.

\section{THE HOLY SEE, THE REPUBLIC AND THE BASQUE CHILDREN: A DIPLOMATIC BATTLE INSIDE THE SPANISH CIVIL WAR}

\begin{abstract}
With the arrival to the Nationalist Spain of Ildebrando Antoniutti, sent by the Holy See with the apparent mission to repatriate the republican Basque children in
\end{abstract}

* El presente trabajo se inserta en el Proyecto de Investigación HAR2010-17955, del Ministerio de Economía y Competitividad. 
exile, it was opened a diplomatic rapprochement through the Holy See and Franco, but the Apostolic Delegate launched also the repatriation of hundred of children. We analyse here different aspects of this non bloody but real fight: the battle for the children. All around Europe there were institutions promoting the return of the children to Spain and other institutions opposing it. This paper, using documentation of the Archivo Gomá, the archive of the Spanish Ministries of Foreign Affairs - both Francoist and Republican - and the Archivio Segreto Vaticano, discuss the diplomatic clash that took place in Europe during the Spanish Civil War, with the children as passive protagonists. This article anticipates a forthcoming book about the role of the Holy See in the repatriation of the Basque children during the Spanish Civil War.

KEY WORDS: Ildebrando Antoniutti, Franco, The Holy See, Spanish Republic, Spanish Civil War, Basque children, Exile, England, Belgium, France, Van Roey, 1936-1939

$\begin{array}{ll}\text { Recibido/Received } & 09-11-2011 \\ \text { Aceptado/Accepted } & 28-02-2012\end{array}$

La que podríamos llamar sin demasiada hipérbole la «batalla por los niños exiliados» $\mathrm{o}$, ciñéndonos a su bloque fundamental, la batalla por los niños vascos - ya que los «basque children» dieron nombre al grupo- ${ }^{1}$ es un aspecto de la guerra civil que tiene carácter transversal, con muchas facetas y matices y que nos alerta ante las simplificaciones. Se puede analizar desde varios ángulos, como pueden ser el humano, el humanitario, ${ }^{2}$ el diplomático o el propagandístico, entre otros posibles. Tiene, además, un marcado componente religioso, tanto por las características del gobierno vasco, que envía al exterior a los niños - acompañados de sacerdotes - , como por parte de quienes los acogieron $-\mathrm{y}$ repatriaron -, que fueron en muchos casos instituciones religiosas - católicas o no- en los países democráticos a los que llegaron. Quedan excluidas de este proceso, por razones obvias, la Unión Soviética y México.

\footnotetext{
${ }^{1}$ En Inglaterra el primer comité creado para la repatriación de los niños se denominó precisamente «Basque Children Committee».

${ }^{2}$ El aspecto humano es quizá el que más se ha tratado en los libros que han tenido una difusión generalizada. El humanitario - a veces en paralelo con el anterior- se estudió también desde el principio, aunque no demasiado a fondo. Haría falta entrar en muchos archivos, de instituciones muy variadas, para poder hacerlo: personas que cuidaron a los niños, organizaciones, fondos recaudados, gastos - con sus beneficios o pérdidas -, atención recibida, etc. Ciertamente, sería un proyecto muy amplio y muy complicado, pero que, si se afrontase, nos daría luces sobre lo que podríamos llamar la «rentabilidad» de la aventura del exilio para sus protagonistas. Rentabilidad en el sentido más realista de la palabra. Es decir, hasta qué punto la vida de los niños exiliados mejoró o empeoró en comparación con los de su generación que quedaron España y tuvieron un punto de partida similar desde el punto de vista económico o social.
} 
Como sobre casi todo lo relacionado con la guerra civil española, sobre los niños vascos se ha escrito mucho, ya desde el primer momento, aunque marcando sobre todo los aspectos humanitarios del drama infantil. De entre las muchas aproximaciones al tema que podrían hacerse, un aspecto que me parece muy significativo desde el punto de vista conceptual e histórico, es el diplomático. Al tratar sobre los niños expatriados y repatriados nos encontramos, en efecto, ante gestiones típicamente diplomáticas, con fuentes que también lo son - aunque otras son administrativas, tanto públicas como privadas - y con actores diplomáticos. Incluso hay más diplomáticos de los que sería normal, y, desde luego, podríamos decir que más de los necesarios: en cada país hay dos representaciones que pugnan por los niños - la republicana y la nacional-, otra semi-diplomática - la Delegación en París del Gobierno de Euzkadi- y finalmente la del enviado especial de Pío XI, que, sin tener unas atribuciones perfectamente delimitadas, como veremos, actuó - como diplomático vaticano que era- no sólo con el respaldo de las nunciaturas sino que también como intermediario ante países que no reconocían a Franco.

La faceta humanitaria, tan mencionada, implica a multitud de actores en toda Europa, desde familias de acogida - que terminaron siendo incluso de adopción - a organismos internacionales como Save the Children o la Cruz Roja, pasando por organizaciones religiosas desconocidas en la España del momento, como el Salvation Army o los cuáqueros, que tuvieron un papel humanitario muy notable en toda la guerra. ${ }^{3}$

La faceta propagandística que suponía colocar en casi todos los países europeos grupos de niños que «huían del fascismo» no se le escapó a nadie desde que el primero de ellos salió de Euzkadi. No pocos de los documentos que he manejado en el archivo del Ministerio de Asuntos Exteriores se clasificaron durante la guerra y por las autoridades republicanas - bajo el epígrafe «propaganda» y, desde luego, la cuestión, como veremos, aparece una y otra vez en casi todas las noticias relacionadas con las repatriaciones. Los niños han sido en toda guerra reciente $-\mathrm{y}$ siguen siendo - un arma impagable de propaganda. Y todo contendiente, a poca oportunidad que le den, acusa al enemigo de ser asesino de niños.

Lógicamente, el aspecto más sensible, más allá aún de lo humanitario, es el humano, los terribles dramas personales que están detrás de los millares de

\footnotetext{
${ }^{3}$ Un libro de época que recoge las memorias del representante del comité de cuáqueros para ayuda a los niños españoles, republicanos y nacionales, ayuda que se prolongó a los refugiados españoles en Francia tras la derrota republicana es el de Kershner, Howard E. 2011. La labor asistencial de los cuáqueros durante la Guerra Civil española y la posguerra. España y Francia 1936-1941. Madrid: Siddharth Mehta Ediciones.
} 
niños que aún hoy lamentan - abierta o veladamente - el desgarrón que el exilio supuso en sus vidas. Niños que tuvieron que dejar a sus padres, su patria y su lengua para emprender un nuevo camino, que - a la vista de los resultados - resultó casi siempre modesto, normalmente encuadrado en lo que en su momento se consideraba proletariado o, como mucho, clase media baja.

Hablar de los niños de la guerra tiene además una dificultad añadida y es su vinculación vivísima hoy en día con la memoria, en el sentido que le da Heers - que considera la historia como la principal arma de asalto que utiliza el Estado actual para apoderararse de la sociedad - en su ensayo sobre L'histoire assassinée:

«Lo que llamamos la Memoria no tiene nada que ver con la Historia. Son dos planteamientos diferentes, muchas veces contradictorios, siempre incompatibles. Hacer memoria lleva a evocar acontecimientos del pasado de una manera emocional, comprometida, para exaltar gloriosas hazañas militares, justificar una determinada empresa o, con frecuencia, incluso para mantener el recuerdo de los momentos difíciles y de los mártires». ${ }^{4}$

En ese sentido, el mantenimiento de la memoria de los niños es variado y amplio. Nos encontramos con completas páginas web como la «Basque Children», 5 con asociaciones de niños de la guerra en Gran Bretaña, con películas como La generación del Guernica [videorecording] 2003, con exposiciones en los pueblos ingleses en los que hubo un contingente significativo de niños, con obras de teatro sobre Morelia (Barcelona, 2008), o con homenajes como el que dio el Ateneo de Madrid a Amalia Solórzano de Cárdenas (Madrid, 2009), o la conmemoración del 75 aniversario de la llegada de los niños a Southampton (2012), entre otras celebraciones.

Esta fuerte implicación personal dificulta casi siempre la labor de espigar los datos entre la carga emocional que tienen los testimonios, en principio históricos, de los protagonistas o, incluso, de los hijos de los actores principales (como Cuauhtémoc Cárdenas, en Madrid), tantas veces solicitados para mantener viva la llama del recuerdo, de la memoria, que no pocas veces resulta precisamente contraria a la historia, en el sentido que le da Heers.

${ }^{4}$ «Ce que nous appelons la Mémoire n'a que peu de commun avec l'Histoire. Ce sont deux démarches différentes, parfois contradictoires, en tout cas incompatibles. Faire mémoire conduit à évoquer des événements du passé de façon émotionnelle, engagée, pour exalter des hauts faits d'armes, justifier telle ou telle entreprise, ou, plus souvent peut-être, pour maintenir le souvenir des heures sombres et des martyrs» (Heers, Jacques. 2006. L'Histoire assassinée. Les pièges de la mémoire: 9. Paris: Éditions de Paris).

${ }^{5}$ Mantienen una excelente página web, con datos sobre colonias, investigaciones en curso, artículos de prensa de época, newsletters y una aceptable bibliografía (http: //www.basquechildren.org, consultada el 11.01.13).

Hispania Sacra, LXV

131, enero-junio 2013, 385-423, ISSN: 0018-215-X, doi: 10.3989/hs.2013.012 
Sin embargo, hay también, junto al cultivo de la memoria, una continuidad y una notable renovación historiográfica sobre estos temas. Desde los primeros momentos tenemos ya tanto novelas ${ }^{6}$ como excelentes relatos documentales de época entre los que destaca el de Cloud y Ellis, sobre Los niños vascos en Inglaterra ${ }^{7}$ que describe muy vívidamente la vida en el campo de Stoneheam, donde se concentraron un tanto caóticamente los primeros centenares de niños enviados a Inglaterra. Es un libro muy completo temáticamente, podríamos decir que muy histórico, que ya incluye cartas, canciones y fotos. En el lado opuesto ideológicamente habría que poner el de Enrique Gabana sobre su - no demasiado afortunada - campaña en Inglaterra para repatriar a los niños. ${ }^{8}$

De estas publicaciones de época, que son casi fuentes - aunque parciales - pasamos ya a publicaciones de los años ochenta, como el libro clásico de Legarreta sobre The Guernica Generation, ${ }^{9}$ el de Gregorio Arrien sobre los Niños vascos evacuados en 1937, ${ }^{10}$ el más reciente de Adrian Bell sobre los niños vascos en el exilio, ${ }^{11} \mathrm{o}$ los numerosos trabajos de especialistas en niños como Alicia Alted o Jesús Alonso Carballés, entre los que destaca el colectivo El exilio de los niños. ${ }^{12}$ Habría que mencionar también los nuevos trabajos sobre propaganda bélica que se están publicando y que incluyen, tangencialmente, la apropiación de los niños con fines propagandísticos. Uno interesante es el de Stradling, ${ }^{13}$ sobre bombardeos y propaganda en la guerra civil, cuya portada es precisamente un cartel propagandístico republicano con un niño muerto, cartel

\footnotetext{
${ }^{6}$ Como la de Kesten. 1945. Los niños de Guernica. Novela. Buenos Aires: Futuro, que relata noveladamente, pero con datos, una síntesis de lo que fue la epopeya de los niños exiliados, desde la salida de España a la llegada a los países de acogida y el trato que se les dispensó: «Nos descargaron, nos contaron, nos examinaron, nos pesaron, nos alimentaron, nos dieron bebidas y, nuevamente en un vagón, despacharon la remesa...» (p. 58). Así sintetiza un protagonista su llegada a Francia. Lógicamente, se centra en historias personales y dramas familiares como el de los niños perdidos en el viaje, las búsquedas desesperadas de madres, los desencuentros entre familias, las tensiones entre familia de sangre y familia adoptiva, etc.

${ }^{7}$ Cloud, Y. y Ellis, R. 1937. The Basque Children in England. London: Victor Gollancz Ltd.

${ }^{8}$ Gabana y Ventura, Enrique. 1939. Mi campaña en Inglaterra. [Barcelona]. Personaje extraño, resulta un tanto sorprendente que Antoniutti - que, lógicamente, no lo conocería demasiado - lo comisionase para gestionar las repatriaciones de los niños refugiados en Gran Bretaña, si dejamos aparte que era probablemente de los pocos sacerdotes disponibles que conocía bien el inglés y a los ingleses.

${ }^{9}$ Legarreta, D. 1984. The Guernica Generation: Basque Refugee Children of the Spanish Civil War. Reno: University of Nevada Press.

${ }^{10}$ Arrien, Gregorio. 1988. Niños vascos evacuados en 1937: álbum histórico, [s. 1.].

${ }^{11}$ Bell, Adrian. 1996. Only for three months: the Basque children in exile. Norwich: Mousehold Press, con traducción española: Bell, Adrian. 2011. Sólo serán tres meses. Los niños vascos refugiados en el exilio. Barcelona: Plataforma.

${ }^{12}$ Alonso Carballés, Jesús et al. 2003. El exilio de los niños. Madrid: Fundación Pablo Iglesias Fundación Largo Caballero.

${ }^{13}$ Stradling. R. A. 2008. Your Children Will Be Next: Bombing and Propaganda in the Spanish Civil War, 1936-1939. Cardiff: University of Wales Press.
} 
del que toma su título el libro. ${ }^{14}$ En éstos nuevos autores sobre la guerra civil entrarían estudios - ambos tesis doctorales - como el de Julio Clavijo, ${ }^{15}$ sobre los refugiados - todos los refugiados bélicos, no sólo los niños - o el de Hugo García,${ }^{16}$ sobre la propaganda bélica, que deja sobrevolar una cierta duda sobre la eficacia de esa propaganda - también con niños - en la opinión pública británica. ${ }^{17}$ Recoge, de algún modo, la polémica anterior que se dio en la historiografía británica sobre el peso real de la guerra civil española en la estructuración de un movimiento coherente en la izquierda británica, polémica que ha trabajado tan excelentemente Tom Buchanan. Por el contrario, Fith planteaba que la guerra civil española había contribuido a construir una especie de frente popular británico, en el que -y es lo que aquí me interesa - las colectas y movilizaciones a favor de los niños tuvieron un gran impacto como catalizador emocional de esa movilización política.

De todos modos, sin perder de vista lo ya publicado, en este trabajo no voy a hacer una revisión historiográfica ni un estudio detallado sobre la misión de Ildebrando Antoniutti, delegado apostólico en España. Es un trabajo que desarrollaré en una futura monografía, recogiendo tanto la acción de la Santa Sede en la repatriaciones como muchas de las interesantes $-\mathrm{y}$ entrañables - cartas de niños exiliados que se conservaron en la Secretaría para la repatriación de niños, establecida en España. ${ }^{18}$ Aquí voy a señalar - apenas - las líneas generales y algunos conflictos del complicado proceso de repatriación, utilizando exclusivamente documentación procedente del Archivo Gomá, ${ }^{19}$ del Archivo del Ministerio de Asuntos Exteriores - de ambos ministerios, el franquista y el republicano- y del Archivio Segreto Vaticano, especialmente del fondo Nunziatura Madrid.

${ }^{14} \mathrm{El}$ trabajo tiene un esclarecedor cuadro comparativo con los datos que sobre un bombardeo -el de Getafe - dieron los periódicos de la época, los recuerdos de los testigos y los historiadores: casi todos son distintos.

${ }^{15}$ Clavijo, Julio. 2002. La política sobre la població refugiada durant la Guerra Civil 1936-1939. Girona: Universitat de Girona.

${ }^{16}$ García, Hugo. 2008. Mentiras necesarias: La batalla por la opinión británica durante la guerra civil. Madrid: Biblioteca Nueva.

${ }^{17}$ A este respecto, conviene tener en cuenta los comentarios de Tom Buchanan sobre la discusión historiográfica acerca del impacto de la guerra civil española en la opinión pública inglesa y, a fortiori, el peso de la propaganda. Vid. Buchanan, Tom. 2011. «Las iglesias británicas ante la guerra civil española», en Antón M. Pazos (ed.), Religiones y guerra Civil española: Gran Bretaña, Francia, España: 19-37. Santiago de Compostela: CSIC.

${ }^{18}$ Se estableció a poco de la llegada de Antoniutti en Bilbao, a cargo del sacerdote Ramón Gríful.

${ }^{19}$ Andrés-Gallego, José y Pazos, Antón M. 2001-2010. Archivo Gomá. Documentos de la Guerra Civil. Madrid: CSIC. 13 vols. 


\section{A SALVO DE LAS BOMBAS}

Niños exiliados aparecen por todas partes durante las guerras, cualquier guerra, pero en la guerra civil española hay un bloque significativo y organizado de niños que salen de España en 1937, poco antes de la caída de Bilbao (19 de junio) - entre marzo y mayo - , bloque que, ya desde el primer momento, fue bautizado en los medios de comunicación y propaganda como los niños vascos. Por supuesto, no todos eran vascos pero, a pesar de eso y de que salieron otros grupos de niños de las zonas del norte - desde Gijón, en septiembreamenazadas por el avance franquista, los niños de Bilbao fueron el paradigma. Hubo expediciones a Francia, Inglaterra, Bélgica, Suiza, Dinamarca, Méjico o la URSS, pudiendo calcularse unos 20.000 niños enviados al extranjero hacia finales de 1937. A lo largo de la guerra, desde luego, muchas veces la prensa habla de niños republicanos o de niños españoles pero, indudablemente, el concepto «niños vascos» resultaba más definitorio, exótico y, además, tenía el valor añadido de ser el bloque original, la referencia de las expediciones infantiles al extranjero. A ello se podría añadir que, para el mundo católico aunque quizá no tanto para el anglosajón - el País Vasco era además un claro territorio de catolicismo político y cultural, que enviaba a sus niños acompañados por sacerdotes que los asistían tanto durante el viaje como después, en las instituciones de acogida, muchas de ellas también católicas. Como se ve, el concepto «niño vasco» tenía en el imaginario católico una carga positiva de la que carecía «niño republicano».

En cualquier caso, el colectivo «niños vascos»o «niños españoles» quedó definido con la llegada a Southampton del mayor contingente de evacuados casi 4000-, que fueron embarcados en Santurce en el vapor «Habana» el 21 de mayo de 1937 y arribaron a las costas inglesas tras día y medio de viaje. Desde este primer viaje se planteó que tales viajes tenían un finalidad clara: poner los niños «a salvo de las bombas». ${ }^{20}$ Es decir, no eran niños enviados al exilio, sino trasladados a un lugar seguro durante una corta temporada para ahorrarles el riesgo de los bombardeos o de la guerra. Esa era la teoría inicial, ya que lo cierto fue que la vida de muchos quedó atrapada en las circunstancias propagandísticas, ideológicas y bélicas que fueron complicando estas - en principio- breves estancias fuera de España. Pero, también porque habían salido con esa finalidad tan clara y por tan poco tiempo, al caer Bilbao se planteó - en el bando vencedor - que era lógico hacerlos regresar a su patria, puesto que los bombardeos de los que huían habían desaparecido definitivamente. Su diáspora carecía ya de sentido. Excepto, como se vio enseguida, en el terreno de la propaganda, dentro de la dialéctica ideológica de la lucha entre fascismo y democracia.

\footnotetext{
${ }^{20}$ Así se titula un artículo sintético, pero muy claro, de Michael Alpert.
} 


\section{ANTONIUTTI Y LOS NIÑOS VASCOS}

La idea de devolver los niños vascos a sus familias, que vivían ya en un territorio pacificado - aunque no pacífico, al menos ideológicamente - quedó clara para las autoridades nacionales desde la toma de Bilbao. Y para muchos, en España y en Gran Bretaña, repatriar a los niños era el final lógico - y baratode una acción humanitaria que había perdido ya su sentido inicial. Y, desde luego, en ambientes no precisamente republicanos se planteaba que lo verdaderamente humanitario era devolver a los niños a su patria, con sus familias y en el entorno natural en que estarían si, unos meses antes, mantenían, no se hubiese tomado la decisión política de expatriarlos innecesariamente con fines propagandísticos.

Entre los que apoyaban la conveniencia de reintegrar a los niños a sus familias estaba la Santa Sede, ${ }^{21}$ por consideraciones humanitarias y religiosas, ya que eran muchas las voces que alertaban de la situación descontrolada en que se encontraban los niños desde una perspectiva personal y formativa, ya que muchos vivían en naciones y - lo que se veía como más grave - en familias no católicas o claramente anti-católicas. El actor fundamental desde el lado vaticano para reintegrar a un ambiente familiar y cristiano a esos niños - en teoría vascos y, consecuentemente, católicos - desperdigados por Europa fue mons. Ildebrando Antoniutti a partir de julio de 1937, es decir, apenas dos meses después de que saliese la primera expedición y al mes siguiente de la caída de Bilbao. En tan poco tiempo, si aceptamos que ésta fue la misión original que se le encomendó a Antoniutti y que sirvió para justificar su venida a España, la Santa Sede tuvo que analizar el problema que planteaban los niños — en puridad, la propaganda generada a partir de los niños - , ver la conveniencia de actuar, decidir que se encargaría de ello el Delegado Apostólico en Albania, llamarle a Roma, ${ }^{22}$ darle el encargo y enviarlo a España pasando antes por París, donde se impuso del problema con Valerio Valeri, nuncio apostólico en Francia.

Ciertamente, la Santa Sede tenía una gran experiencia de repatriaciones y atención de prisioneros, desarrollada en la I guerra mundial, pero en España no la había ejercido directamente durante la guerra civil. Tanto los canjes de prisioneros como las pesquisas sobre soldados del Corpo Truppe Volontarie perdidos en combate, que solicitaban sus familiares italianos al papa, se habían evacuado

\footnotetext{
${ }^{21} \mathrm{Al}$ parecer, Pío XI tuvo un gran interés desde el primer momento por los niños vascos, manifestado en recomendaciones especiales al secretario de Estado y en aportaciones ecnómicas (cfr. Cárcel Ortí, Vicente. 2008. Pío XI entre la República y Franco. Angustia del Papa ante la tragedia española: 317. Madrid: BAC).

${ }^{22}$ El 15 de julio de 1937 recibió un telegrama del card. Pacelli convocándolo a Roma para una misión temporal no especificada (Cfr. Cárcel Ortí, Vicente. 2008: 307).
} 
hasta el momento eficazmente a través del card. Gomá, primado de España y representante oficioso de la Santa Sede..$^{23}$

Con todo, aceptada la explicación de que Antoniutti vino a repatriar niños, - y no en misión exploratoria, como una primera aproximación diplomática de la Santa Sede a Franco, una vez aceptado como encargado de negocios el marqués de Aycinena, aceptación que comunicó el propio mons. Antoniuttihay que reconocer que su llegada a España fue ciertamente atípica. En efecto, la primera noticia que se tuvo de su llegada - contra toda práctica vaticana, muy dada a las indagaciones previas - fue mediante un telegrama de Pacelli a Gomá en el que informaba de que el papa había decidido enviar a Bilbao - no a España, genéricamente - a mons. Ildebrando Antoniutti, hasta ese momento delegado apostólico en Albania, con un encargo muy específico: ver si sería posible y cómo sería factible reunir a los niños vascos expatriados con sus familias. Y, consecuentemente, pedía a Gomá que consiguiese plena libertad de movimientos para el enviado vaticano. ${ }^{24}$

En ese mismo telegrama se le notificaba que llegaría a España por la frontera de Irún. Casi hubiese podido indicar que ya estaba esperando en el puesto fronterizo para entrar en España, porque el telegrama llegó después de que Antoniutti hubiese salido de Roma. La precipitación del viaje fue tal que sorprendió a Gomá fuera de Pamplona, en Santiago de Compostela, donde había ido a recibir en nombre de la Iglesia la ofrenda al Apóstol que tradicionalmente realizaba la autoridad civil en tiempos de la monarquía y que Franco acababa ${ }^{25}$ de restaurar. E inmediatamente llegó, podríamos decir que casi después del enviado, una carta de Pacelli presentando a mons. Antoniutti y su misión.

La ira del secretario de Gomá al recibir esta información es una de las más desatadas de toda su correspondencia. Y conocemos su reacción precisamente

${ }^{23}$ En el Archivo Gomá se conservan súplicas remitidas por la Secretaría de Estado vaticana de madres italianas que solicitaban ayuda para saber algo de sus hijos, combatientes en España. La mayoría de las veces se trataba de soldados de los que sus familias no tenían noticia desde hacía tiempo. En ocasiones se acompañaba copia de la carta recibida en el Vaticano, casi siempre de personas muy humildes que escribían al obispo local o directamente al papa pidiendo ayuda. Normalmente el card. Gomá pedía informes a las autoridades militares y, cuando recibía respuesta, la remitía a Roma. Lógicamente, no siempre se conseguía averiguar el paradero del soldado en cuestión, que en no pocas ocasiones se clasificaba como desaparecido en combate.

${ }^{24}$ «Santo Padre ha deciso inviare a Bilbao Monsignore Antoniutti Ildebrando, attualmente Delegato Apostolico Albania, col incarico di studiare specialmente, di intesa concordandosi (V.E.R.) se ed in qual modo sia possibile procurare il ritorno dei fanciulli baschi, alle loro familia Punto Prego V.E.R. procurare il libero ingresso e movimento di detto Prelato» (en Andrés-Gallego, José y Pazos, Antón M. 2001-2010. En adelante, AG, con indicación de tomo (primera cifra) y documento (segunda cifra). En este caso, AG 6-408, Pacelli a Gomá, 21.VII.1937, p. 530.

${ }^{25}$ Hacía apenas unos días, el 21 de julio de 1937. 
por estar Gomá fuera de Pamplona, su residencia habitual. Luis de Despujol, personaje interesantísimo y de gran influencia sobre Gomá durante la guerra - fue una verdadera eminencia gris - , le escribió, nada más recibir el telegrama, una carta incendiaria en la que no se recataba de utilizar terminología casi mafiosa - macarroni, padrone - para referirse a los prelados vaticanos:

«Mi respetado y querido Sr. Cardenal: Ha llegado el adjunto papelito ${ }^{26}$ de los «macarroni». Por la gravedad que encierra y por todas las consecuencias que puede traer consigo he propuesto al $\mathrm{Sr}$. Obispo ${ }^{27} 1^{\circ}$ mandarle el telegrama que ya debe haber recibido para que aguardara ahí la carta y pudiera consultar el caso con ese Sr. Arzobispo; ${ }^{28} 2^{\circ}$ remitirle el texto íntegro para que pudiera realizar aquellas gestiones que sean del caso. Permítame ahora decirle francamente lo que pienso. Con toda la crudeza y libertad. Esto es una jugada más de toda la chusma que merodea por aquella santa casa. Se ha dado cuenta que V.E.R. dice las cosas como son y al decirlas caen a contra pelo, pues les interesa creer lo contrario. Por lo mismo mandan un hombre que por mucho que quiera decir la verdad no la dirá porque su afán será quedarse aquí de N[uncio]. y naturalmente todo su esfuerzo ha de ser el contentar a su «Padrone» alias Mgs. P. ${ }^{29}$ Además, tenga la seguridad que los de la flamante ex-República harán todo lo posible para acapararlo y ponerlo a su diapasón. Y aquí está todo el enorme peligro: toda la ralea que se mueve en $\mathrm{B}[\mathrm{ilbao}] .^{30}$ verán en dicho viajero un elemento de defensa y de acusación: de defensa ante ultramar; ${ }^{31}$ de acusación contra F[ranco]. en ídem. Vea, pues, todo lo que puede suponer la presencia de ese señor. Tanto más que el motivo a más de ofensivo para F. es completamente ridículo, ya que no tienen que hacer más que emprender el viaje de regreso: nadie les ha de poner dificultad alguna para regresar a sus casas».32

Lo que más irritó a Despujol, ${ }^{33}$ catalán marcadamente antinacionalista, fue que el enviado pontificio decidiese instalarse precisamente en Bilbao, en

\footnotetext{
${ }^{26}$ Se refiere a la carta de Pacelli presentando a Antoniutti y explicando la misión que lo traía a España.

${ }^{27}$ José Cartañá Inglés, obispo de Gerona, entonces refugiado en Pamplona, amigo y estrecho colaborador de Gomá durante toda la guerra.

${ }^{28}$ Tomas Muniz de Pablos, arzobispo de Santiago, a donde había ido Gomá para responder, en nombre de la Iglesia, en la ceremonia de Ofrenda al Apóstol realizada tradicionalmente en nombre del rey y ahora restaurada. La Ofrenda, por designación de Franco, la hizo el general Fidel Dávila, en nombre del jefe del Estado.

${ }^{29}$ En este caso se trataría de Eugenio Pacelli, secretario de Estado y superior jerárquico de Antoniutti.

${ }^{30}$ En principio lo que más molesta a de Despujol es que vaya precisamente a Bilbao, en contacto directo con los ambientes del clero nacionalista vasco. No hay que olvidar que de Despujol consideraba tan negativamente a los nacionalistas vascos y su gobierno que fue el que hizo que Gomá cambiase el título de la carta abierta al presidente Aguirre, sustituyendo presidente por señor. Una pequeña prueba de su escaso reconocimiento al, según él, «llamado» Gobierno de Euzkadi.

${ }^{31}$ Es decir, el Vaticano. Normalmente, en la correspondencia de confianza, Gomá y sus corresponsales lo suelen llamar así.

${ }^{32}$ AG 6-425, Despujol a Gomá, 24.VII.1937, p. 547.

${ }^{33}$ Despujol fue un hombre clave durante guerra, no sólo como eficacísimo secretario de Gomá, sino por su influencia sobre el propio cardenal al que llevó en no pocas ocasiones a posturas más radicales de
}

Hispania Sacra, LXV

131, enero-junio 2013, 385-423, ISSN: 0018-215-X, doi: 10.3989/hs.2013.012 
contacto con los aún numerosos eclesiásticos afines al PNV. Sin embargo, a pesar de ésta difícilmente empeorable impresión inicial, tras unos días acompañando al «viajero», como le llama en clave en su correspondencia con Gomá, empezó a ver que la misión de Antoniutti era también exploratoria, con vistas a un reconocimiento diplomático por parte de la Santa Sede:

«Naturalmente que al lado de esto se va dibujando más cada día que es objeto también del viaje una información de «visu» sobre las cosas de esta tierra. No tengo que decirle que procuro con discreción y tacto llevar el agua a nuestro molino. // Mi impresión es la siguiente: En Secretaría de Estado ha causado y hecho mucha mella cuanto ha dicho V.E.R. sobre este país, pero al propio tiempo les parecía imposible que fueran tan locos y criminales los dirigentes. Estando así llegó la carta particular de V.E.R. a manos del Card. Pacelli y esta carta les hizo ver el gran peligro que corrían aquí cosas sagradas. Combinaron entonces la doble jugada de mandar la carta para el reconocimiento oficial del encargado oficioso y al mismo tiempo ocuparse de los niños y darse cuenta de lo que aquí ocurre». ${ }^{34}$

De hecho, lo que mons. Antoniutti vio en esos días, le iba a convencer, al menos aparentemente, de que la situación no era exactamente como el PNV y los sacerdotes vascos exiliados la planteaban en Roma. En uno de esos días, contaba Despujol a Gomá,

«estuvimos en Ochandiano, Elorrio y Durango. En Ochandiano tan pronto se dieron cuenta de la presencia de un Obispo se llenó la iglesia donde están en los altares las imágenes profanadas por los rojos: sin ojos, sin nariz, o sin manos, etc. Quedó horrorizado. La gente llorando se le acercaba a besar el anillo y cuando estaba en la calle los gritos a Cristo Rey, al Papa y España como al Generalísimo eran incesantes. Fue realmente emocionante por lo espontáneo. Nos acompañó el Vicario General. A la noche hablando conmigo tuvo comentarios durísimos sobre los dirigentes que habían engañado y explotado a este pueblo creyente y dócil y sobre los principales culpables a su juicio, es decir los curas. Me decía que en realidad para // darse cuenta del hecho incomprensible de que los católicos vascos hayan podido ir del brazo con los rojos únicamente puede comprenderse viniendo al país y apercibirse de que el pueblo fue engañado totalmente lo que aumentaba la responsabilidad de los dirigentes y de los sacerdotes. No le cabe en la cabeza que así haya sido. Claro que por mi parte procuro que esta impresión y severo juicio se acentúen en cuanto las circunstancias me lo permiten. Pero tengo la impresión de que saldrá de España y de esta tierra vasca completamente asegurado».35

las adoptadas inicialmente. Hijo del marqués de Palmerola y cuñado de Juan Ventosa, último ministro de Hacienda de Alfonso XIII, tenía excelentes contactos, también fuera de España, y notable capacidad de gestión que puso en práctica en esos años. Una breve semblanza en Cárcel Ortí, Vicente. 2006. "Luis Despujol Ricart", en Diccionario de Sacerdotes diocesanos españoles del siglo xx: 380-381. Madrid: BAC. Falta una biografía, que sería de las más interesantes - y originales - del clero catalán del siglo $\mathrm{XX}$.

${ }^{34}$ AG 7-36, Despujol a Gomá, 5.VIII.1937, p. 59.

${ }^{35}$ AG 7-36, Despujol a Gomá, 5.VIII.1937, p. 60. 
Lógicamente, los primeros contactos de mons. Antoniutti fueron con las autoridades, Franco en primer lugar, que le recibieron excelentemente - todo lo contrario de lo que había sido su llegada a la frontera - con una acogida «tan calurosa y servicial que le ha llenado de asombro y reconocimiento».36

Con el único representante oficial con el que hubo distanciamiento fue precisamente - aunque quizá habría que decir lógicamente- con el encargado de la repatriación de niños dentro del patronato de protección de menores, Antonio Maseda Bouso: ${ }^{37}$

«En Burgos [Antoniutti] visitó al General Dávila y al General Jordana. Uno y otro estuvieron atentísimos y así me lo expresó el Viajero. Se entrevistó también con el Sr. Maseda. La impresión de esta visita ya no fue tan agradable, debido al hecho de que se sacó la impresión que en realidad no tienen nada organizado en serio. De hecho tiene más datos concreto[s] el Viajero que el llamado Comité de Burgos, que está reducido al Sr. Maseda... quien se ausenta y naturalmente cuando está fuera no se hace nada. // No he podido aclarar si las reticencias que tuvo el Sr. Maseda se deben a que no estaba bien enterado o bien a las instrucciones que haya podido haber recibido en el sentido de que se mantenga reservado con el Viajero. Esto último me parecería un poco extraño (aunque muy posible) ya que en las alturas se han dado cuenta del gran bien que puede hacerles el hecho de que el Papa intervenga en la cuestión de los niños, pero haciéndolo de acuerdo con Salamanca». ${ }^{38}$

\section{En una segunda visita Despujol comentaba a Gomá:}

«Seguimos tropezando con la actitud algo rara del Sr. Maseda quien se muestra receloso. Es difícil aclarar el motivo, pero el Viajero sigue impertérrito su camino con gran discreción y calma y tengo la seguridad que todo se irá poniendo bien». ${ }^{39}$

De hecho, mons. Antoniutti conquistó a todos sus interlocutores. El propio Gomá, normalmente perspicaz para juzgar a las personas, le escribe a Muniz

\footnotetext{
${ }^{36}$ AG 7-45, Despujol a Gomá, 6.VIII.1937, p. 69.

${ }^{37}$ La organización estatal - un tanto precaria - para la repatriación de los niños enviados al extranjero se había puesto en marcha en mayo, inmediatamente después de la primera expedición, dependiendo de Antonio Maseda. Poco después se organizaría con más medios, quizá ante el estímulo de las gestiones de Antoniutti. Sobre la Delegación de repatriación de menores franquista ver Alted Vigil, Alicia. 1999. "Le retour en Espagne des enfants évacués pendant la guerre civile espagnole: la Délégation extraordinaire au rapatriement des mineurs (1938-1954)", en VV.AA., Enfants de la guerre civile espagnole. Vécus et représentations de la génération née entre 1925 et 1940: 47-59. Paris Montreal: L'Harmattan.

${ }^{38}$ AG 7-36, Despujol a Gomá 5.VIII.1937, pp. 58-59.

${ }^{39}$ AG 7-45, Despujol a Gomá 6.VIII.1937, p. 69.
} 
de Pablos, arzobispo de Santiago, ciudad en la que estaba el cardenal cuando apareció improvisamente mons. Antoniutti en la frontera:

«Ahora veo que me pide impresiones sobre Mr. Antoñito. ${ }^{40}$ Me gusta: es listo y simpático. Y de mucho juicio y de mucho mundo. Creo que ha tenido acá una gran «decepción»: se ha encontrado con una España españolísima, con buen pan y hasta tortas y que lo de la otra parte es algo nauseabundo. No me cabe duda de // que su viaje será de gran utilidad, para España y para Roma. Yo creo que será la revalorización del voto de todos nosotros, puesto en entredicho durante un año. He tenido con él dos largas conversaciones. Me ha confesado que la información de la otra parte, especialmente vasca y catalana, ha sido tremenda en contra y hasta de algunos Hermanos de la parte blanca; ¿los adivinaría V., cuando hemos visto tanta «unanimidad», al menos en los papeles y conversaciones?». ${ }^{41}$

En cualquier caso, mons. Antoniutti siempre planteó en sus entrevistas oficiales - y privadas - que venía a repatriar a los niños. De hecho, como reconoce Despujol, tenía al llegar más información que la del correspondiente departamento oficial del gobierno franquista.

La ventaja de mons. Antoniutti era que - aunque oficialmente no era sino un delegado apostólico con una misión caritativa - disponía de todos los resortes de la diplomacia pontificia. Y los utilizó desde el principio. Envió una circular a los nuncios o arzobispos de los principales países involucrados, circular que, dentro de la habitual corrección formal de la correspondencia pontificia, exigía que secundasen sus peticiones con decisión, actuó como intermediario en países que no tenían reconocida a la España nacional o financió, con fondos vaticanos, los gastos de repatriación que no cubrían los organismos locales.

En cualquier caso, de ser cierto que Pío XI estaba preocupado por la propaganda contra la España católica que se hacía utilizando a los niños exiliados, la llegada de mons. Antoniutti reavivo las tensiones que tenía lugar en toda Europa en torno a los exiliados.

\section{INDOCTRINAMIENTO INFANTIL}

Que los niños habían sido enviados al exterior como objetos propagandísticos fue algo que se denunció desde los primeros momentos tanto en la prensa como en muchos comunicados - discursos, libros o pastorales - del mundo católico europeo de entonces. Así, L'Avvenire d'Italia de 27 de octubre de 1937

\footnotetext{
${ }^{40}$ Le sigue la broma a Tomás Muniz de Pablos, bastante guasón, que tradujo así al español el apellido italiano del delegado apostólico. El arzobispo de Santiago era un andaluz, completamente contrario en carácter a Gomá, que resulta siempre serio en sus cartas, excepto con Muniz.

${ }^{41}$ AG 7-280, Gomá a Muniz, 31.VIII.1937,p. 298.
} 
encabezaba su información sobre «L'opera della Santa Sede per il ritorno dei fanciulli baschi alle loro famiglie», - información escrita con motivo de la pastoral, que reproducía, de mons. Lauzurica ${ }^{42}$ pidiendo la vuelta de los niñoscon una declaración de principios: «fueron enviados al extranjero por orden del cesado Gobierno Vasco y, generalmente, contra la voluntad de los padres, sobre todo por razones de propaganda política». ${ }^{43}$

Le Métropole de Amberes, de 25 de agosto de 1937, era igualmente explícito:

«Hay que denunciarlo ante el mundo como un nuevo escándalo, y quizá el peor de todos: ese éxodo enorme de niños vascos fue una innoble explotación de los rojos, organizada con una fin propagandístico, sin preocuparse de los sufrimientos que provocaría, para conmover al mundo ante la suerte de una población que querían presentar como huyendo con horror ante unos sanguinarios rebeldes». ${ }^{44}$

De hecho, incluso los que no hacían juicios de valor y aceptaban que la intención del exilio era proteger la vida de los niños, podían ver cómo niños y propaganda eran dos caras de la misma moneda, aspectos que, aunque se dieron en todas partes, tuvieron más fuerza en unos países que en otros.

El concepto propaganda hay que considerarlo tanto hacia fuera - usando a los niños en actos antifascistas o pro-republicanos - como hacia dentro, tiñendo el exilio infantil de indoctrinamiento político. Desde el punto de vista católico la propaganda que se consideraba más perniciosa $-\mathrm{y}$ ahí estaría la raíz ideológica de la batalla por los niños - era la segunda, es decir, la que se hacía no tanto con los niños sino sobre los niños, mediante la influencia que ejercían sobre ellos las instituciones o familias que los acogían. Evidentemente, estas críticas partía de un presupuesto: se trataba de niños bautizados y, por tanto, miembros de la Iglesia católica que, en condiciones normales, hubieran vivido en un entorno católico, el habitual en el País Vasco. La conclusión era clara. Esos niños, también en el exilio debían crecer en un ambiente similar al de sus pueblos o, al menos, que no fuese contrario a su fe y a la fe de sus padres. Por supuesto que, del mismo modo que no todos los «niños vascos» era vascos, tampoco todas las familias de los exiliados eran católicas. Incluso podría haber niños no bautizados, algo que se daba en los entornos socialistas vascos en los años treinta. Pero,

\footnotetext{
${ }^{42}$ Administrador apostólico de la diócesis de Vitoria, en sustitución de mons. Múgica, expulsado de España por la Junta de Defensa de Burgos en los primeros meses de la rebelión militar.

${ }^{43}$ Archivio Segreto Vaticano (en adelante, ASV Arch.Nunz.Madrid 975, Stampe, 487r.

${ }^{44}$ «Il faut le crier au monde comme un nouveau scandale, et peut-être le pire de tous: cet exode massif des enfants basques fut une ignoble exploitation des rouges, organisée par eux dans un but de propagande, sans souci des souffrances qu'elle engendrait, pour apitoyer le monde sur le sort d'une population présentée comme fuyant épouvantée devant les rebelles sanguinaires!» (ASV, Arch.Nunz.Madrid 975, Stampe, 490r).
} 
en principio, de acuerdo con el estereotipo vigente, se partía de la identificación entre español y católico, y más aún en Euzkadi.

Así se entiende la preocupación de una monja española, Sor Catalina Corral, Hija de la Caridad, que escribía desde St. Etienne a Antoniutti para «suplicarle emple[as]e toda la fuerza de su poder para arrancar de manos indignas, más ignorantes que culpables, este número de niños y jóvenes que se dicen // Refugiados Españoles» [...] y que estaban, según ella, en una situación «donde todo les falta en el orden moral». ${ }^{45}$ Evidentemente, se refería a niños acogidos por organizaciones socialistas y comunistas.

En la misma línea iba la consigna que lanzó la revista infantil Pelayos, de tendencia carlista y de gran tirada entonces - hasta ser fagocitada por la Falange - cuando pidió a sus pequeños lectores que «re[zasen] cada día un Padrenuestro, por los niños españoles deportados, para que Dios no permita que sus almas se perviertan». ${ }^{46}$

Con argumentación parecida, el representante oficioso del gobierno franquista en Bélgica escribía al ministerio informando sobre un niño al que sus padres - en este caso, parece que católicos - querían repatriar:

«Hecha la correspondiente encuesta se ha averiguado por el hijo mayor, de 14 años, Ignacio González Cortes, que se encuentra alojado en casa de una familia socialista que no practica la religión católica y el chico hace un año que no ha ido a la Iglesia. La persona que informa a esta Representación dice que hablando con el muchacho pudo darse cuenta de que las gentes que lo rodean le hacen creer una serie de atrocidades que dicen ocurren en la España Nacionalista. Esta impresión suya pudo comprobarla hablando con otro niño español, el que no tenía más que ideas falsas de la vida en nuestra Patria; ideas que naturalmente les inculcan las familias que los han recogido.// Debo indicar a V. E, que la madre cree que sus pequeños han sido acogidos por familias católicas, siendo muy otra, en efecto, la triste realidad». ${ }^{47}$

La potencial descristianización en el extranjero de los niños — básicamente los alojados con familias protestantes, comunistas o socialistas - se presentaba como algo no sólo preocupante sino que debía pesar gravemente sobre la conciencia de los padres. Así lo planteaba el sacerdote belga que escribía al director de la oficina de repatriación de la Santa Sede relatando el drama humano y, sobre todo, desde su punto de vista, religioso, de los hermanos Zarandona, un apellido inequívocamente vasco:

\footnotetext{
${ }^{45}$ ASV, Arch.Nunz.Madrid 977, fasc. 4, 449r.

${ }^{46}$ ASV, Arch.Nunz.Madrid 975, Stampe, 493r.

${ }^{47}$ Archivo del Ministerio de Asuntos Exteriores (en adelante AMAE), R-1260, 43 f. 2. En el archivo del Ministerio de Exteriores se conservan las dos series de documentación, la franquista y la republicana, lo que permite, muchas veces, ver los mismos hechos desde puntos de vista opuestos.
} 
«Desde hace dos días deseo escribirle sobre los niños Zarandona para que, si puede, haga saber a sus padres lo siguiente:

Contrariamente a lo que su padre se imagina, los niños no están bien. Son como criados, por supuesto sin sueldo, en la pobre casa donde están. Además del grave inconveniente en que en mi otra carta aludí que sobra repetir en ésta, que no se imagine el padre que aprenden bien el francés. ¿Qué francés podrán aprender con una mujer del campo flamenca, que sería la primera que debería empezar por aprenderlo?

Por último y lo más importante: No logro que esos niños vengan a la Iglesia. No he logrado que vayan a misa ni una sola vez no obstante la carta del papá, que leí a la mujer y al hombre que han recogido a los Zarandona. ¿Qué apoyo puedo encontrar en un medio socialista?

Le agradeceré que haga saber a la madre todo esto para que no se imagine que sus hijos están bien aquí, por el contrario. Sus padres son los que han de dar cuenta a Dios de esto». ${ }^{48}$

\section{PROPAGANDA CON NIÑOS}

Con todo, esa propaganda que podríamos llamar silenciosa, y que quizá resultó la más radical, al menos en las vidas de muchos de los exiliados, no fue la más llamativa. Es más, apenas se le ha dedicado atención. Ni por la prensa de la época, ni por los historiadores del exilio. Llamaba mucho más la atención, ya que eso era - y es - lo que normalmente se entendía por propaganda, el uso o la presencia de niños en actos políticos o manifestaciones, casi siempre a favor de la República, aunque no sólo.

Lo más habitual era que participasen en marchas políticas, normalmente contra la guerra o contra la no intervención. Funes, desde la embajada republicana en Bruselas, informaba al ministerio el 16 de septiembre de 1938 sobre una manifestación encabezada por «la Diputado Isabelle Blume y Estelle Goldstein, Secretaria de la Federación de Bruselas», en la que había niños, utilizados como refuerzo de las consignas antibelicistas:

«El domingo 11 de septiembre ha tenido lugar en Bruselas una manifestación organizada por la Federación de Mujeres Socialistas a la que asistieron cerca de 2.000 ciudadanas. Figuraban en ella numerosos carteles con inscripciones como la siguiente: «Queremos proteger a los niños españoles contra los bombardeos» [...] El primero de los carteles reseñados era seguido de un importante grupo de niños españoles albergados por los socialistas de Bruselas». ${ }^{49}$

${ }^{48}$ ASV, Arch.Nunz.Madrid 977, fasc. 4, 505r.

${ }^{49}$ AMAE, R-629, 76, f. 9. 
Pero, y eso quizá era más útil en países menos apasionados, como Gran Bretaña, los niños también aparecían en actos públicos, que eran ocasión de propaganda encubierta. El cónsul de España en Glasgow, Enrique Salazar, informaba al ministerio el 17 de agosto de 1938 que 12 niños vascos refugiados en Carlysle habían pasado unos días en Glasgow.

«Invitados por el Jefe de la Exposición imperial de Glasgow, los niños españoles acudieron el Miércoles de la semana pasada al Pabellón de la Paz, en cuyo monumento, que lo constituye un montículo formado por piedras conmemorativas, colocaron una piedra española. A este fin fui invitado para recibir a los niños en la Exposición, explicarles el sentido del Pabellón de la Paz, sus alegorías, sus fotografías, etc., y tomar parte en el acto de la colocación de la piedra. Después de colocada ésta, y requerido para ello por el jefe del Pabellón, le hablé a los niños sobre el sentido del acto que acababan de realizar y de cómo ellos, en cuanto buenos españoles, deseaban paz para todo el mundo y para nuestro país en particular, si bien condicionada ésta última por la independencia absoluta de España y por el triunfo de su República democrática»..$^{50}$

De hecho, como ya vimos, muchos de los informes diplomáticos sobre niños eran clasificados en el ministerio bajo el epígrafe «Propaganda».Así, el que envió desde la Legación de España en Berna Antonio Fibra Ribas, el 12 de diciembre de 1938, acompañando recortes de prensa sobre un sesión del «Guignol Lyonnais» organizada por los «Amigos de la España republicana» de Ginebra el 8 de diciembre de 1938 en la Casa comunal de Plainpalais. Ciertamente, el acto era ya muy tardío, con la guerra casi terminada, y los participantes eran catalanes, no vascos, pero iba en la línea de aprovechar la presencia de niños exiliados para reforzar el compromiso humanitario con la causa republicana:

«Es de advertir que el Departamento de Instrucción Pública de Ginebra había prohibido al citado «Guignol» toda propaganda en las escuelas del Cantón, pero al espectáculo de Plainpalais acudieron numerosos niños ginebrinos, aportando cada uno un regalo para los niños de Gerona». ${ }^{51}$

Algo similar se daba en España. Desde luego, en la batalla ideológica, la España nacional aprovechaba, siempre que había oportunidad, la expatriación infantil para condenar al marxismo-separatismo o al anarco-separatismo, responsables, para el franquismo, del envío de los niños al extranjero. ${ }^{52}$

\footnotetext{
${ }^{50}$ AMAE, R-895, 48, f. 12.

${ }^{51}$ AMAE R-634, 98.

${ }^{52}$ A modo de ejemplo, en el Heraldo de Aragón del 20 de julio de 1938 se informaba de que "Ochenta y ocho niños procedentes de Bélgica llegarán mañana repatriados a Irún. [...] Fueron arrancados de sus hogares por los rojo-separatistas" (AMAE R-629, 76, f. 17) y la Gaceta [del Norte (?)] titulaba en un caso similar: «Ciento sesenta y tres niños arrojados al destierro por el odio anarco-separatista, llegan hoy a sus casas» (ASV, Arch.Nunz.Madrid 975, Stampe, 553r).
} 
De ahí que las repatriaciones, aunque respondieran directamente a gestiones realizadas por Antoniutti, fuesen utilizadas espectacularmente por el nuevo Estado para propaganda interna y externa, ya que aprovechaban también el impacto de la noticia en la prensa del país que los repatriaba. Por lógica, las más cuidadas, por tratarse de un país clave y por ser de las primeras, fueron las repatriaciones británicas, que fueron utilizadas como galvanizador patriótico entre la población vasca animándola - casi obligándola - a acudir a recibir la expedición. La puesta en escena de la acogida a los primeros ciento cincuenta y dos niños llegados de Inglaterra resultó un espectacular alarde de propaganda de masas:

Tras llegar en tren, «Los niños se trasladaron al exterior de la estación y tomaron los cinco tranvías engalanados que habían sido puestos a su disposición. Se inició la comitiva, dando escolta a los coches los Flechas y Pelayos. Abría marcha la Banda Infantil de Música. Detrás un piquete de gastadores de los Flechas, los cinco tranvías conduciendo a los expedicionarios, rodeados por los Flechas y Pelayos, que portaban antorchas, dando una nota espectacular al desfile; a continuación las banderas victoriosas y, finalmente, la Banda de F. E.T. [...] En todo el recorrido un público numerosísimo, que formaba calle, ovacionó a los pequeños, que correspondían con vítores a España y a su Caudillo. A las diez menos veinte de la noche llegaron los niños a la Subdelegación, ante la que se había estacionado numeroso público. Los salones de aquella, adornados con gusto exquisito, merced a una deferencia de «La Innovación», acogieron a los repatriados, a los que se sirvió una espléndida cena por las muchachas de Auxilio Social [...] Los familiares que acudieron a recoger a los pequeños esperaron en un salón contiguo a que éstos cenaran y se hicieron cargo de ellos con las formalidades del caso».53

Por supuesto, la rentabilidad de la recepción no quedó reducida a la prensa local o a los que participaron en los actos. La Gaceta del Norte informaba el 17 de noviembre de 1937 que

\begin{abstract}
«Desde el micrófono de Radio España de Bilbao ha hablado Mr. D. P. Mc Guire, destacada personalidad del campo de las letras inglesas, que ha venido a Bilbao acompañando a los niños vascos repatriados. Mr. Mc Guire habló a sus compatriotas de las consoladoras realidades de la España nacional, vistas por ellos. Es digno de gratitud el gesto de los caballeros ingleses que han venido a nuestra villa con ocasión del regreso de nuestros niños expatriados». ${ }^{54} \mathrm{Y}$ el periodista concluye, con toda lógica que «después de su visita han de ser, con mayores motivos, propagandistas en su país de la justicia de nuestra Cruzada Nacional».
\end{abstract}

También iba en la línea de la contrapropaganda la información que se difundió en Gran Bretaña intentando mostrar la falsa postura de la prensa

${ }^{53}$ ASV, Arch.Nunz.Madrid 975, Stampe, 506r.

${ }^{54}$ ASV, Arch.Nunz.Madrid 975, Stampe, 554r.

Hispania Sacra, LXV

131, enero-junio 2013, 385-423, ISSN: 0018-215-X, doi: 10.3989/hs.2013.012 
pro-republicana en la isla, que presentaba a Franco como «the baby Killer». En un artículo que analizaba la oposición del Basque Children Committee a las gestiones de Antoniutti, se decía:

«Franco, el «mata niños». Desgraciadamente, sin duda a causa de su fuente de inspiración, han llegado a la convicción de que el General Franco es el genuino asesino de niños; y han mantenido esa postura, inasequibles a las pruebas en contra, y empapados de una conmovedora fe en los distintos «gobiernos» españoles»..$^{55}$

El corresponsal del Catholic Herald, enviado con los niños repatriados en noviembre de 1937, recoge la historia de una madre, que - casualmente - trabajaba en el hotel de Zarauz donde se había alojado el corresponsal, y que le informó de que

«Al acercarse los nacionalistas, en septiembre de 1936, los rojos la amenazaron con matarla a ella y a su hijo si no acompañaba a las tropas en retirada hacia Bilbao. A los siete meses de estar allí, le dijeron que se había arreglado todo para enviar a su hijo a Inglaterra. $\mathrm{Al}$ principio, las cartas del niño eran estupendas ya que todo era una divertida aventura $[\ldots]$ «Creo que estaba muy contento al principio - todo eran novedades - pero ahora sus cartas son cada vez más tristes». ${ }^{56}$

En el otro bando, un corresponsal de prensa holandés, a su vez, - también casualmente - tuvo la fortuna de presenciar cómo un padre anarquista que iba a despedir a su hijita herida en la ambulancia que la llevaba a Francia coincidía en la frontera con los pilotos alemanes causantes del bombardeo que iban a ser entregados en un canje. La narración tiene tal carácter propagandístico que el cónsul de España en Ámsterdam lo remite al ministro, convenientemente traducido, con el membrete de «Subsecretaría de propaganda». ${ }^{57}$

No se le dio menos uso en la zona nacionalista, donde el niño expatriado fue usado en la prensa para fomentar el combate contra «el ogro marxista», como

\footnotetext{
${ }^{55}$ «Franco the «Baby Killer». Unfortunately, due no doubt to the source of inspiration they seem to have started auto with the conviction that General Franco was the natural baby killer; they have retained this conviction against fearful odds together with a touching fait for various Spanish «Governments»» (Catholic Herald, 20.VIII.1937, «Basque Children's Committee. Disagreement With Papal Delegate», en ASV, Arch.Nunz.Madrid 975, Stampe, 502r.).

${ }^{56}$ «At the approach of the Nationalists in September, 1936, the Reds threatened to kill her and her son if she refused to accompany the retreating forces to Bilbao. After seven months there she was told one day that arrangements had been made to send her boy to England. At first cheery letters came from the child who found it amusing adventure [...] «I think he was quite happy at first - the novelty of it all - but you will see that his letters get sadder and sadder» (Catholic Herald, 12.XI.1937, en ASV, Arch.Nunz.Madrid 975, Stampe, 492r.

${ }^{57}$ AMAE, R-636, 25.
} 
mostraba una portada de la revista infantil carlista Pelayos $^{58}$ o se calificaban directamente las expatriaciones como «trata de niños», como recogía una viñeta de Domingo, periódico de San Sebastián, del 25 de julio de 1937, justo el día de la llegada de Antoniutti a España, aunque la coincidencia no es más que eso.

\section{LA SANTA SEDE Y EL IMPULSO DE LAS REPATRIACIONES}

La batalla propagandística se enconó precisamente tras la venida de Antoniutti y el comienzo sistemático de las repatriaciones. Al desaparecer el peligro de guerra en el País Vasco, la repatriación empezó a ser vista como algo deseable desde el punto de vista humanitario - sobre todo en ambientes católicos -, desde el punto de vista ideológico ${ }^{59}$ - especialmente en el territorio franquista - y desde el punto de vista político, al menos en el parlamento inglés, donde el ministro de Interior planteó el 4 de noviembre del 37 que «the sooner the children go back to their families the better» ${ }^{60} \mathrm{En}$ el caso inglés, la presión ambiental para sacar a los niños de Gran Bretaña fue tal que los mismos campeones de la acogida a los niños veían difícil justificar que siguiesen fuera del país vasco desde el momento en que ya no había peligro de guerra allí.

Es más. Incluso los intentos de frenar el regreso de los niños empezaron a tener mala prensa, sobre todo a partir del otoño de 1937. El Catholic Herald de 15 de octubre de 1937 calificaba - y así lo titulaba - la resistencia de las organizaciones de acogida a devolverlos a su tierra como «cruellest thing that could be» .

El propio embajador Azcárate veía como imparable el movimiento y urgía al gobierno de la República para que intentase frenar el golpe. En telegrama del

\footnotetext{
${ }^{58}$ Pelayos, 5 de septiembre de 1937. La portada muestra a un gigantesco mejicano con numerosos niños entre sus brazos que es atacado a bayoneta calada por pequeños «pelayos» que intentan rescatarlos. El pie del dibujo decía: «Pelayos. El ogro marxista nos ha robado millares de hermanitos».

${ }^{59}$ La preocupación ideológica de la Falange por lo que consideraban influencia negativas sobre los niños expatriados la sintetizó Ramón de Olascoaga en Diario Vasco de 30 de enero de 1938 en un artículo titulado «La repatriación de los niños y la educación totalitaria» dedicado a glosar los logros del fascismo en la educación de la juventud. Según él, la urgencia de la repatriación de los niños era ideológica: «Y era oportuno y urgente el proceder así [repatriarlos sin esperar al fin de la guerra], porque, según han podido notarlo los observadores directos, ya se manifiestan en algunos de los niños repatriados resabios de marxismo y de desespañolización, cuyos gérmenes llevarían, directamente muchos, en sus almas infantiles, y han encontrado allí, en el extranjero, el clima y los medios apropiados para su cultivo. Para impedir, pues, la consumación total y perfecta de tan repugnante crimen contra el espíritu, la España Nacional acepta, gustosa, cualquier sacrificio» (ASV, Arch.Nunz.Madrid 975, Stampe, 530r).

${ }^{60}$ Bell, A. 1996: 91.
} 
22.II.1938 al ministro de Instrucción Pública planteaba su delicada posición para resistirse a la corriente repatriadora:

«Envío hoy duquesa Atholl, Presidenta, enérgica carta insistiendo envío mil niños Francia se hizo a fin evitar envío Bilbao niños no reclamados padres y subrayando gravedad abandono por Comité criterio mantenido hasta ahora no devolver niños sin garantía estaban libremente reclamados padres.- Cuestión puede agudizarse y dado elementos políticos representados Comité conviene alejar más posible Embajada discusión a fin evitar riesgo pueda quedar afectada cordialidad mis relaciones con duquesa, Roberts y otros elementos políticos representados comité. Sugiero envío persona autorizada». ${ }^{61}$

Empezaban las discusiones. A partir de ese momento la presión para repatriar desató las disputas en los distintitos países y entre los distintos comités que habían recibido niños.

\section{LA GUERRA DE LOS COMITÉS}

Y en esas discusiones sobre la conveniencia o no de repatriar a los niños la cuestión clave terminó siendo, lamentablemente para los protagonistas pasivos, una cuestión muy práctica: ¿a quién pertenecen los niños? Ciertamente no se formuló así, pero ésa fue la clave para el destino de los niños, y destino strictu sensu, que marcó absolutamente sus vidas. Para los entornos más legalistas - como podía ser el comité británico de juristas - , religiosos - sobre todo entre los católicos y protestantes neutros - o nacionalistas, los niños pertenecían a sus padres. Para los ambientes socialistas y, sobre todo, comunistas, los niños, con más o menos matices, eran del Estado, precisamente lo que les recriminaban sus contrarios en las constantes polémicas de esos años. De todos modos, al margen de teorías y desde el punto de vista práctico, que fue el que en realidad se aplicó, podríamos decir que los niños pertenecían a los comités. Si el comité responsable -el que los había recibido en custodia - decidía repatriar, los niños volvían a España, sin que influyeran demasiado las presiones diplomáticas o políticas para evitarlo. Si el comité «propietario» se resistía, casi siempre conseguía bloquear las peticiones de repatriación, incluso paternas, argumentando que los padres no actuaban libremente, sino bajo presión de las autoridades franquistas.

Precisamente el choque entre la ideología y la realidad práctica es lo que subyace en las primeras crisis del National Joint Committee for Spanish Relief. El duque de Alba, con profundo conocimiento de la psicología británica, había

\footnotetext{
${ }^{61}$ AMAE, R-895, 48, f. 25.
} 
planteado la conveniencia de constituir un nuevo Comité ${ }^{62}$ para oponerlo al Basque Children's Committee, el cual técnicamente era un «Sub-Committee of the National Joint Committee for Spanish Relief» y al que la prensa católica veía como abiertamente parcial y favorable de los enemigos de Franco. ${ }^{63}$

El problema con que se encontró el nuevo comité, sin embargo, fue que la custodia de los niños, de acuerdo con la postura del gobierno británico, era responsabilidad exclusiva del primer comité receptor:

«desgraciadamente, - afirmaba un artículo del Catholic Herald - el Gobierno de Su Majestad, al confiar la custodia de los niños al National Joint Committee, lo ha colocado en una posición legal tan fuerte que es prácticamente inatacable y actuará como soberano mientras el Gobierno no tome cartas en el asunto». ${ }^{64}$

Por tanto, las primeras escaramuzas se orientaron, a deslegitimar los «comités-propietarios» que impedían la repatriación. A esas alturas, entrando el otoño de 1937, el representante del obispo local en el Leeds Basque Children's Committee había presentado su dimisión, ya que estaba

«convencido de que la política de seguir ayudando a los niños en ese territorio estaba condenada al fracaso y de que resultaría además una fuente de penalidades insoportables tanto para los propios niños como para los padres a los que pertenecían». ${ }^{65}$

La postura católica en los comités era coherente con el planteamiento genérico de la Iglesia: los auténticos responsables de los niños eran los padres y, por tanto, las peticiones de los padres debían ser atendidas. Y, dado que, aunque lentamente, se fue imponiendo esa visión, el paso siguiente fue conseguir que los padres pidiesen la repatriación. Para ello se hicieron llamamientos en la prensa del país vasco desde le primer momento, sobre todo a aquellos padres - socialistas, fundamentalmente - que podían tener motivos para aplazar la petición.

\footnotetext{
${ }^{62} \mathrm{La}$ misma idea se planteó en Bélgica, donde Ernesto de Zulueta -inicialmente representante franquista, después embajador - propuso crear un comité civil para negociar con los distintos grupos y organizaciones que no se encuadraban dentro de la Obra del Cardenal de Malinas, que era claramente favorable a los franquistas (ASV, Arch.Nunz.Madrid 976, fasc. 2, 314r).

${ }^{63}$ «A body avowedly partisan and supporting the enemies of Nationalists», según lo calificaba el Catholic Herald, 22.X.1937.

${ }^{64}$ «Unfortunately, H. M. Government, by entrusting the guardianship of the children to the National Joint Committee, have placed the latter in so strong a legal position that their control is virtually unassailable, and their will sovereign until the Government itself acts», en Catholic Herald, 22.X.1937.

${ }^{65}$ «Convinced that the policy of helping the children any longer in that country is doomed to failure, and will result in untold hardships and injury to the children themselves and to the parents to whom they belong», en Catholic Herald, 22.X.1937.
} 
« ¿Se aperciben los padres que quieran de veras a sus pequeños de la necesidad de aportar los datos que insistentemente les venimos pidiendo desde La Gaceta del Norte? $[\ldots]$

Terminamos repitiendo lo que ya hemos anunciado otras veces. El Secretariado de la Comisión Pontificia encargada de la repatriación de los niños está instalado en Bilbao, en la calle de Hurtado de Amézaga, número 24, piso segundo.

¡Padres de niños expatriados!... ¡A Acudid a ese Secretariado!... ¡ Aportadle todos cuantos datos queráis!... ¡No os detenga ni la consideración de que alguno de vosotros tenga la desgracia de no ser católico!... La grandeza de la Iglesia y la bondad del Soberano Pontífice no quiere saber más que vuestro corazón de padres está angustiado para acudir en vuestra ayuda y devolveros vuestros hijos». ${ }^{66}$

Va en la misma línea, aprovechando en este caso la capilaridad de la organización parroquial católica que llegaba al rincón más remoto, el texto que escribió Antoniutti para que se leyera en las misas dominicales de Euzkadi. El escrito pretendía mover a los padres que aún no lo habían hecho a que reclamasen la vuelta de sus hijos. Estaba planteado de manera dramáticamente convincente ya que sugería la posibilidad de que, con el paso del tiempo, los niños terminasen siendo enviados a Rusia, algo que sonaba $-\mathrm{y}$ lo fue realmente - como la peor opción de cara a una futura recuperación de los expatriados. Desde luego, en la correspondencia que se conserva, se puede apreciar que los padres ven Francia, Bélgica o Inglaterra como lugares civilizados, cercanos - aún teniendo en cuenta la percepción de las distancias de la época- e incluso deseables para la educación de los niños, que podían recibir allí no sólo una buena educación sino también aprender otro idioma. Rusia, en cambio, era un riesgo demasiado alto.

\section{LA RESISTENCIA A REPATRIAR: «BAJO El AMPARO DE LA REPÚBLICA»}

Como en todo, las campañas pro-reclamación de niños que se hicieron desde el bando nacional fueron convenientemente contrarrestadas en el campo republicano. Y el procedimiento fue muy parecidos. Básicamente, consistió también en llamamientos hechos a través de prensa a los padres republicanos para que escribieran contra la repatriación de sus hijos. Se pretendía así bloquear las posibles peticiones de otros familiares - abuelos o tíos, normalmente - que podían estar en el bando contrario.

Las cartas oponiéndose a la repatriación llegaron en muchos casos a los países de destino a través de los canales diplomáticos de la República y se inició, también aquí, una batalla de cartas. En ocasiones, cada uno de los padres pedía

\footnotetext{
${ }^{66}$ ASV, Arch.Nunz.Madrid 975, Stampe, 491r.
} 
una cosa. Lo normal fue que el cónyuge que estaba en España pidiese la repatriación y el que estaba en el exilio se opusiese. Valga como ejemplo el escrito enviado al embajador en Bélgica por la Dirección General de Evacuación y Refugiados del Ministerio de Trabajo acompañando la carta de una madre para que su hijo

«permanezca en esa nación, bajo el amparo de la República, sin permitir se tome en consideración cualquier petición, sea de la persona que fuere, por la que se solicitara el traslado de dichos niños [sic] a territorio faccioso». ${ }^{67}$

La idea básica era precisamente ésa: que los niños en el extranjero estaban «bajo el amparo de la República», igual que si estuviesen en territorio leal, por lo que devolverlos a España era visto como una traición a la República y a los propios niños. Parafraseando la terminología bélica, era como pasarse al enemigo. Lógicamente, estos llamamientos republicanos fueron contrarrestados también por la contra-propaganda. La prensa británica pro-franquista denunciaba - y traducía literalmente - un llamamiento del gobierno de Euzkadi en La Vanguardia de Barcelona, de 27 de noviembre de 1937, pidiendo que quienes tuviesen niños en Inglaterra escribiesen al «Basque Children's Committee» en Londres o al Departamento de Bienestar del Gobierno Vasco en Barcelona (que se encargaría de remitirlas a Londres)

«dejando claro que sus hijos no deben abandonar Inglaterra y ordenando, si no pueden seguir en el país, que sean enviados a zona leal o a Francia, bajo el control de las autoridades republicanas».$^{68}$

Esto, lógicamente, introduce un factor relevante que va más allá del mero humanitarismo y plantea el carácter claramente político de la batalla por los niños. Según estos planteamientos, los niños no habían sido enviados por sus padres a un lugar seguro para huir de la guerra. Habían sido enviados por la República y a ella debían volver o, si no, a territorio neutral o amigo, que era considerado como una especie de República española extraterritorial. El problema era que eso resultaba cada día más irreal conforme avanzaba la guerra.

Y por supuesto, en este tira y afloja con los niños, una vez metidos en propaganda y contra-propaganda, los documentos falsificados estaban a la orden del

\footnotetext{
${ }^{67}$ AMAE, R-629, 74, f. 7.

${ }^{68}$ «Stating that their children must not leave England, and ordering, if they cannot remain in that country, that they be sent to loyal territory or to France, under the control of the Republican authorities», se dice en una información titulada «Reds Trying to Get Basque Children», probablemente del Catholic Herald, en ASV, Arch.Nunz.Madrid 975, Stampe, 514r.
} 
día. ¿Cómo podía pensar el card. Van Roey de Bélgica que la entrañable carta firmada por Pepita de Ansola, muy preocupada por su hijo, en la que le decía que

«estoy muy agradecida del trato y educación que dan sus primos a mi hijito, pero como parece que alguien se ocupa de hacerle llevar a Bilbao, valiéndose de firmas falsa, bien sea mía como de mi esposo, debo de decirle que es mi deseo que mi hijo siga donde está hasta que termine la guerra o tenga un hogar donde poder llevarle», ${ }^{69}$

iba a venir seguida de otra que denunciaba a la autora como falsa madre y en la que se pedía exactamente lo contrario?:

«Mucho nos ha extrañado que nos hayan remitido la reclamación que habíamos hecho de nuestro hijo Rafael. En la Delegación Pontificia nos han dicho que eso era debido a que la madre desde Francia negaba que nadie reclamase su hijo y que toda reclamación que de él se hiciese debía ser tenida como falsa. Nada más falso que esto, Emmo. Sr.: precisamente tanto el padre como la madre estamos en Bilbao y aquí hemos permanecido durante todo este tiempo de guerra». ${ }^{70}$

Realmente, las situaciones de perplejidad no debía de ser pocas para los comités que actuaban de buena fe, incluso aunque el caso extremo de varios «padres» pidiendo cosas opuestas fuese poco frecuente. Así, por poner un ejemplo que complicaba aún más las deliberaciones de los comités, no debía resultar fácil decidir lo correcto cuando la falsificación de personalidad había estado no al final del proceso, es decir, en el momento de pedir la repatriación, sino al principio, en el momento al enviar el niño al extranjero. En una consulta que el 8 de febrero de 1938 hizo el cónsul belga en España a Antoniutti, le planteó el caso de un niño que, al producirse la sublevación, estaba con sus tíos en la zona «roja» mientras que el padre había quedado del lado «nacional». Los tíos lo habían enviado al extranjero haciéndolo pasar por hijo suyo y el padre real lo reclamaba ahora, «por lo que dado lo especial del caso me permito exponerlo a V.S. para que de mutuo acuerdo veamos qué se puede hacer para complacer a estos padres», terminaba diciendo el cónsul, evidentemente favorable, como el gobierno belga en general, a la repatriación. ${ }^{71}$

Batalla por tanto, niño por niño. Pero batalla también global, ya que, al mismo tiempo, se intentó frenar en bloque las peticiones, todas. La estrategia fue diferente en cada país, aunque las armas que se usaron fueron las mismas. El planteamiento más amplio - aunque, como veremos, no el más eficaz - tuvo carácter jurídico y fue diseñado por el gobierno de la República para poder tener

\footnotetext{
${ }^{69}$ ASV, Arch.Nunz.Madrid 976, fasc. 2, 257r.

${ }^{70}$ ASV, Arch.Nunz.Madrid 976, fasc. 2, 258r.

${ }^{71}$ ASV, Arch.Nunz.Madrid 976, fasc. 2, 330r-331r.
} 
jurisdicción sobre los niños fuera de España. Si esto se aceptase internacionalmente, es decir, si las autoridades republicanas pudieran actuar sobre los niños exiliados lo mismo que si estuvieran en territorio nacional, sí se haría realidad que estaban «bajo el amparo de la República». Y, consecuentemente, sólo las autoridades republicanas podrían decidir sobre la suerte de los niños. Fue una solución demasiado legalista, podríamos decir, más que legal, que se articuló en dos pasos. El primero fue un decreto de la presidencia del Consejo de Ministros de 15 de octubre de 1937 (Gaceta del 17.X.1937) ampliando la jurisdicción consular en el extranjero de modo que ésta alcanzase a la tutela de menores,

«a cuyo efecto [los cónsules] serán reputados como Jueces de menores, con las mismas atribuciones y sujetas a las mismas formalidades que establecen o establecieren las Leyes, Decretos y ordenes de los Tribunales de Menores de España».

\section{El decreto se complementó con una}

«orden del Ministerio de Justicia de 19 de octubre de 1937 - (Gaceta del 21) - estableciendo las normas a que se han de sujetar los Cónsules de España en el extranjero, en cuanto a la jurisdicción que le ha sido atribuida de Jueces de menores por el Decreto anterior»..$^{72}$

El problema, que no pasó inadvertido desde el primer momento a los diplomáticos republicanos, fue que la República estaba legislando sobre territorios soberanos extranjeros. De hecho la duda - casi podríamos decir la certeza sensu contrario - sobre la oportunidad de estas medidas llevó enseguida al Ministerio de Estado a solicitar un dictamen a su asesoría jurídica, dictamen que - aunque prudente - resultó demoledor, no sólo en cuanto a la viabilidad práctica de las normas que se dictaban, sino incluso acerca de la legalidad del proyecto en el ámbito del derecho internacional vigente:

«No incumbe a esta Asesoría entrar a comentar a fondo dicho Decreto, sino su interpretación y efectos.

Formula, sin embargo, sus reservas sobre la viabilidad de una disposición que, en suma, extiende, por declaración unilateral, la jurisdicción del Estado español en orden a la tutela legal y función pública correctiva de menores -institución de carácter público- a países extranjeros.

Es suficiente la lectura del Decreto de 6 de agosto de 1937 -(Gaceta del 8) - sobre organización de instituciones tutelares de menores y, concretamente, el artículo $13^{\circ}$, para

${ }^{72}$ AMAE, R-629, 11, f. 13. 
percatarse que, difícilmente, soportará ningún Estado una infracción tan evidente del principio, generalmente admitido, de la territorialidad de las leyes penales, de policía y de seguridad pública». ${ }^{73}$

\section{El CASO BELGA}

En la práctica se vio que, tal como habían pronosticado los servicios jurídicos, el decreto quedó, como tantos otros de la época, limitado a las páginas de la Gaceta. Y, además, las páginas de la Gaceta no lograban traspasar las fronteras españolas, ni siquiera físicamente, si tenemos en cuenta las quejas del embajador belga, cuando intentó usar este decreto para parar las expatriaciones. El embajador, en un intento un tanto desesperado de frenar la devolución a España de los niños que estaban bajo control del arzobispo de Malinas, exploró las posibles vías jurídicas internacionales para bloquear los procesos en marcha, aunque sin demasiadas esperanzas ya que los niños eran reclamados en debida forma con todos los requisitos pedidos por la justicia belga. Por ese lado pensaba que no había manera de oponerse con éxito ante los tribunales locales. Quedaba la posibilidad de intentar argumentar con el nuevo decreto, pero, sorprendentemente, ya que en Bélgica había muchos niños republicanos refugiados, no le había llegado, pues hacía meses que no recibía la Gaceta. No sabía por tanto a qué atenerse con respecto a las posibilidades de la nueva ley. En la práctica, el aislamiento en que se encontraba era una prueba más de la desorganización interna republicana que no conseguía ya ni colocar el texto de sus leyes allí dónde más se necesitaban:

«El problema jurídico - escribe al Ministerio - es el siguiente. Las Autoridades eclesiásticas afirman poseer la prueba documental de que los padres reclaman a sus hijos en uso de las facultades inherentes a la patria potestad. Tales reclamaciones se hacen por cartas enviadas a los colaboradores del Arzobispo, por documento notarial, bajo la $\mathrm{Fe}$ de la persona que ejerce esta función en territorio rebelde o ante la Autoridad municipal facciosa del domicilio de los padres.

En los dos últimos casos el Cónsul honorario de Bélgica legaliza la firma de la representación oficial que advera el documento. Los documentos afirman la voluntad de los padres, pero no resuelven un problema que afecta al consentimiento y que se relaciona con el hecho de que esa manifestación de voluntad no es espontanea y está en casi todos los casos obtenida mediante coacción. Los juristas belgas a quien se ha consultado el caso están conformes con este criterio. Pero opinando también que si el padre reclama al hijo no hay posibilidad de que prospere ante estos Tribunales una oposición y si la manifestación de voluntad se produce ante el Cónsul de Bélgica en el domicilio del padre, es plenamente válida para la justicia belga, que estimará suficiente y legítima la fe de sus

\footnotetext{
${ }^{73}$ AMAE, R-629, 11, f. 13 r-v.
} 
representantes en el extranjero, aunque estos Cónsules honorarios puedan ser españoles rebeldes». ${ }^{74}$

El embajador, con muy buena lógica, pensaba que para oponerse a la vuelta de los niños apoyándose en el decreto de 6 de agosto de 1937 era

«preciso disponer del texto legal del Decreto y de sus disposiciones complementarias, todas contenidas en números de la «Gaceta» que hasta hoy no han llegado a esta Embajada, a pesar de haberse reiteradamente reclamado» [...] por ser los números correspondientes a Julio de 1937 los últimos que hemos recibido». ${ }^{75}$

De todos modos, ahí apuntaba una estrategia que podía tener posibilidades y que fue la que se siguió. Consistió en rechazar las peticiones por considerarlas forzadas, como consecuencia de las presiones franquistas sobre los padres que estaban en su territorio para que reclamaran a sus hijos. Evidentemente, esto era un juicio de intenciones que, como el mismo embajador pensaba, no sería aceptado por los tribunales belgas ni por el arzobispado de Malinas. Sin embargo, sí pareció funcionar - aunque no siempre - con los niños belgas bajo control de la Cruz Roja. Es decir, volvemos a ver el poder de «propiedad» que las distintas agrupaciones de acogida tuvieron de facto sobre los niños:

«Pero [en Bélgica, informaba el embajador] hay otra institución que alberga niños españoles, el Comité Janson, organismo neutro, que funciona en relación con la Cruz Roja de Bélgica. Este Comité se ha dirigido a la Embajada para hacerle conocer peticiones de padres enviadas desde la zona rebelde. Las demandas venían avaladas por las autoridades facciosas. Hemos rechazado siempre su legitimidad y hemos pedido que las manifestaciones de los padres se produjeran ante las autoridades consulares belgas. [...] El Comité Janson planteó recientemente la cuestión de que no le era posible obtener las debidas garantías de parte de los Cónsules y que tenía que conformarse con la voluntad de los padres, recogida por las Autoridades rebeldes. Con estas mínimas formalidades, probablemente simuladas o falsas, han sido expedidos a la zona rebelde unos cinco niños. No importa el número sino el hecho». ${ }^{76}$

Para la Cruz Roja se llegó a un acuerdo con el Comité Janson que partía de la dudosa libertad que tenían los familiares que estaban en la «zona facciosa» para evitar las presiones instándoles a reclamar el regreso de sus hijos, por lo que se investigaba a fondo cada caso, se intentaba interrogar a los padres, si era posible, o se procuraba, al menos, deducir sus disposiciones sobre la situación de sus hijos en el extranjero por medio de las cartas que conservasen los niños. Finalmente se decidió

\footnotetext{
${ }^{74}$ AMAE, R-629, 76, f. 31.

${ }^{75}$ AMAE, R-629, 76, f. 32.

${ }^{76}$ AMAE, R-629, 11, f. 2-3.
} 
«que un Comité restringido, compuesto de tres personas, una dama católica, la Secretaria Mme. Cornil, cuyas simpatías por nosotros no ofrecen duda, y el mismo Senador Rolin, decida la solución a adoptar en cada caso». ${ }^{77}$

En este caso estaba claro que, independientemente de las posibles acciones jurídicas de la Embajada, a las que se veía poco futuro, se contaba al menos con elementos favorables en el comité que debía decidir. Era justo lo contrario de lo que sucedía en otros comités, como el dependiente del arzobispado, donde la Embajada no tenía ninguna influencia. En este caso se procuró alcanzar un acuerdo de mínimos. Es decir, se negoció una cláusula negativa: no repatriar contra la voluntad de los padres. El acuerdo se limitó a los niños que vivían en Bélgica pero las condiciones resultan tan poco claras $-\mathrm{y}$ al mismo tiempo tan amplias - que cabe dudar o de su aplicación o de la precisión con que el embajador informaba:

«El Padre Janssens ha prometido a esta Embajada, siempre por correspondencia, dos cosas: no enviar ningún niño cuyos padres se opongan al traslado, conformándose a este efecto con la manifestación de la Embajada, sin necesidad de documento alguno complementario y repatriar exclusivamente los que sean reclamados de un modo expreso por sus padres». ${ }^{78}$

En el fondo, lo que queda claro en la lucha por las repatriaciones es que la propiedad de los niños era una cuestión «de facto». Ni el embajador republicano - reconocido oficialmente, aunque, en el caso belga, con poco entusiasmo por parte del gobierno local - ni el representante del gobierno de Euzkadi - católico - tenía capacidad de presión alguna sobre quienes acogían de hecho a los niños.

De ahí que las informaciones de Ruiz-Funes sobre sus relaciones con el cardenal Van Roey tengan a veces un toque de humor - un tanto negro - motivado por su impotencia para actuar. Una aplicación del clásico reír para no llorar.

Ya de entrada partía de que el cardenal ni siquiera le consideraba interlocutor, por lo que intentó que la negociación la hiciese alguien del gobierno vasco:

«he intentado reiteradamente, en posesión de una paciencia ascética, ponerme en relación con su Eminencia, mereciendo, unánimemente, la repuesta de su desdén. [...] Cuando vino a Bruselas el Sr. Monzón, Delegado del Gobierno Vasco, se aquietó mi espíritu. El Sr. Monzón podía entablar el diálogo con Su Eminencia en términos de correcta ortodoxia. Su Eminencia lo recibió y el Sr. Monzón obtuvo de él la promesa de que no

\footnotetext{
${ }^{77}$ AMAE, R-629, 11 , f. 3

${ }^{78}$ AMAE, R-629, 11, f. 1.
} 
enviaría a los pobres niños que albergaba a reanudar la inquieta vida que antes habían llevado bajo los ataques facciosos». ${ }^{79}$

El «ortodoxo» diálogo de Monzón con Van Roey no tuvo demasiado efecto en esa negociación, ya que el cardenal no sólo no consideraba especialmente la opinión de los representantes del gobierno vasco, sino que, al parecer, los vejaba. Atascada la negociación indirecta con el arzobispado - vía Gobierno vasco-, el embajador intentó obtener, al menos, informaciones concretas sobre los niños españoles a través de las autoridades belgas, que, en teoría, deberían poseerlos:

«Convenzido [sic] de que el Arzobispo Jefe de la Iglesia belga, tendría respecto a mi una opinión poco confortadora, decidí obtener de los Burgomaestres de las ciudades donde se albergan los niños traídos a Malinas, que son los de la jurisdicción archiepiscopal, las obligadas referencias. Tampoco las he conseguido. Acudí entonces a la Dirección de Seguridad que debía poseer esos datos. No los poseía. Todo ello me ha llevado a la conclusión de que la jurisdicción de $\mathrm{Su}$ Eminencia tiene el rango de un Estado». ${ }^{80}$

En cualquier caso, los pactos entre Monzón y el cardenal Van Roey, si se dieron, desde luego, no se cumplieron, y al ver que empezaban las primeras repatriaciones, el embajador republicano intentó ponerse en contacto con la delegación del gobierno vasco en París:

«El Sr. Mújica me dijo que había asegurado al Sr. Monzón, advertido por la Embajada de mis temores, que no se llevarían a un sólo niño. Era la promesa del Arzobispo. Esto ocurría a las 10 de la mañana del martes 18 [de enero de 1938]. A las 11 en punto, partieron en unos vagones, con las iniciales P. L. M. expresamente unidos al tren, unos doscientos niños, acompañados del P. Janssens, del Abate Glibert [sic], de 4 maestras vascas, entre ellas la Srta. Pilar Acedo, y de varios Sacerdotes y Religiosas. Al arrancar el tren, muchos de los niños lloraban, sin que al parecer encontrara eco su dolor en los evangélicos señores que les acompañaban. En un tren posterior salieron sus modestos equipajes. El proyecto era conducir a los niños directamente a Hendaya, haciendo el paso por París, desde la Estación del Norte al Quai d'Orsay por un ferrocarril de cintura. Todo estaba previsto. La jurisdicción exenta de su Eminencia, tiene por lo visto, el alcance internacional. Todos estos detalles, oportunamente comunicados por nuestro servicio de información, los di a conocer a la Delegación Vasca en París». ${ }^{81}$

El desanimado embajador terminaba comentando al ministro:

\footnotetext{
${ }^{79}$ AMAE, R-629, 76, f. 39.

${ }^{80}$ AMAE, R-629, 76, f. 40.

${ }^{81}$ AMAE, R-629, 76, f. 43-44.
}

Hispania Sacra, LXV

131, enero-junio 2013, 385-423, ISSN: 0018-215-X, doi: 10.3989/hs.2013.012 
«Espero que V. E. podrá comprobar por la lectura de este informe que Su Eminencia goza de un verdadero poder sobrenatural en la vida política belga». ${ }^{82}$

MÁS ALLÁ DE LA LEY

Desde luego no todos los receptores de niños eran legalistas, ni todos los repatriadores jugaban limpio. El sentirse propietarios de los niños - al menos «de facto»- llevaba a que organismos menos respetuosos con el derecho burgués, - como lo calificaban-, negasen incluso capacidad a los padres para reclamar a sus hijos. Una carta del 30 de enero de 1938 que escribe el hermano - emigrado en Fontaine, Francia - de un padre reclamante, después de entrevistarse con el comité que custodiaba a la niña, manifiesta cómo la resistencia podía llegar a concretarse en norma no escrita:

«pues he recibido la reclamación que has hecho para la repatriación de tu hija y deseguida nos habemos presentado Begoña y yo junto del Comité que está responsable de los niños que han venido de esa y nos han dado muy pocas esperanzas o casi ninguna es decir nos han dicho que en este momento no estaban dispuestos a mandar niños a España ni de una parte ni de la otra porque igual podía haber bombardeos de una parte que de la otra y luego yo le he dicho en presencia de la muchacha, sí pero en vista de que es su padre que la reclama y que su firma está legalizada por el Cónsul de Francia en Bilbao no veo de que derecho podemos rehusar una hija a sus padres, y a esto él me ha dado a entender que son ellos al fin me han tomado el documento de mi mano diciendo que lo presentarían a las autoridades francesas y que si éstas accedían a tu súplica que tal vez la muchacha sería repatriada así es que estamos en la espera y si de aquí unos días yo no recibo aviso alguno favorable pues volveré a ver a esos Sres. y te diré lo que me han dicho ${ }^{83}[\ldots]$

En otros casos, el rechazo del derecho vigente era tan claro como la brutal respuesta que recibió una monja que atendía la colonia minera de españoles de St. Etienne, en Francia:

«Me he querido ocupar de varios niños entre ellos Consuelo y Ángeles Rodríguez [...] sus padres están en el Campo de concentración como detenidos; después de recibirme muy mal la persona que los tiene me ha contestado entre otras cosas: Estos niños, no los doy ni a su mismo padre que se presente; es al comité Comunista que pertenecen».

De todos modos, en este caso la respuesta, aunque significativa, era retórica, ya que la propia monja aseguraba «que su mismo padre en efecto, como ayer leí

\footnotetext{
${ }^{82}$ AMAE, R-629, 76, f. 45.

${ }^{83}$ ASV, Arch.Nunz.Madrid 977, fasc. 4, 506r.
} 
en una carta, no quiere que salgan de aquí», frase con la que concluía su carta a Antoniutti, angustiada por el futuro de esos niños. ${ }^{84}$

La formalización de esa propiedad era casi siempre, como vimos en Gran Bretaña, por desistimiento de los gobiernos a entrar en la cuestión del exilio infantil, dejando que los distintos comités acordaran entre ellos la mejor solución. En Bélgica, el 1 de noviembre de 1938 hubo una reunión de los distintos grupos, perfectamente clasificados en adictos o contrarios:

«P. O. B.; Socorro Popular; Cruz Roja de Bélgica; Grupo de Defensa de la República Española, todos adictos y «Retour au Foyer» y Delegados del señor Arzobispo de Malinas, contrarios. Presidió la reunión el Administrador de la Seguridad Pública que expresó que la reunión había sido convocada a demanda del comité de Amberes «Retour au Foyer» que se ocupa de la repatriación de niños españoles bajo disimulados auspicios del señor Arzobispo de Malinas. El Comité había solicitado del Ministro de Justicia que se le autorizara a repatriar todos aquellos niños cuyo envío a la zona facciosa fuera autorizado por sus padres. El Administrador dijo que la seguridad incumbe únicamente al control de extranjeros y que sólo los Comités pueden decidir sobre la repatriación de los niños, y si no hay acuerdo entre ellos, corresponde la solución del caso a los Tribunales de Menores» ${ }^{85}$

Recientemente se ha investigado algo la actividad desarrollada por grupos falangistas, ya en la posguerra mundial, que realizaron prácticas de secuestro de niños para traerlos a España. Si entendemos el término secuestro en sentido lato, ya a finales de 1938, en la misma reunión que acabo de mencionar, se cruzaron acusaciones de secuestro de niños que eran «propiedad» de otros comités:

«El señor Boldo, en representación del Grupo español de Defensa de la República, aludió a las actividades del Comité de Amberes «Retour au Foyer» manifestando que se dio a conocer por un hecho que podría calificarse de verdadero secuestro de niños. En efecto recogió a las niñas Concepción Díaz Muruaga, albergada en Verviers por el señor Herbillo, que luego fue recuperada y sacó de las casas donde habitaban a las niñas Pilar y Carmen García Muñoz, igualmente reintegradas a sus hogares, a todas con el propósito de enviarlas a la zona facciosa. Todo ello se hizo sin la intervención del Comité responsable. Estas denuncias produjeron sensación y el representante del «Retour au Foyer» manifestó por toda excusa, que tenía noticias de que los Comités responsables y los niños albergados carecían de toda comunicación con los padres de esos niños, a lo que respondió el señor Boldú que esa relación existe y se mantiene con la mayor continuidad posible» ${ }^{86}$

Evidentemente, para secuestrar a alguien, aunque sea con intención de ayudarle, o de rescatarle, que de todo hubo, lo primero es saber dónde vive. De ahí que el símbolo o, mejor, la llave del poder sobre los niños fuesen las listas de

\footnotetext{
${ }^{84}$ ASV, Arch.Nunz.Madrid 977, fasc. 4, 449r. Carta de sor Catalina Corral a mons. Antoniutti.

${ }^{85}$ AMAE, R-629, 76, f. 3r. Informe del embajador Mariano Ruiz-Funes de 1 de noviembre de 1938

${ }^{86}$ AMAE, R-629, 76, f. $4-5$
} 
direcciones, celosamente custodiadas por cada comité. Igual que el embajador en Bélgica se asombraba de no poder conseguir las listas de los niños bajo control del arzobispo de Malinas, también la prensa católica inglesa titulaba con asombro «Home Office has no list of basque children», con todo lo que eso significaba:

«El extremo más llamativo respecto a esta lista es que ni siquiera el ministerio de Interior tiene una copia. Esto quiere decir que el Basque Committee tienen el control absoluto sobre el destino de los niños y eso independientemente no sólo de los católicos o los nacionalistas, sino incluso del legítimo gobierno de esta nación». ${ }^{87}$

Las listas llegaron a ser objeto codiciado y, por tanto, susceptibles de espionaje o de robo. El embajador en Bélgica informaba el 28 de enero de 1938 sobre una maniobra, con ribetes de espionaje, que atribuía a los católicos, destinada a apoderarse de direcciones de niños de comités republicanos:

«Mlle. Parkmans ha acogido en su propia casa a una maestra católica vasca, la Srta. Pilar Acedo, que le denunció primero el proyecto [de una próxima repatriación de niños] y que a [sic] partido después con la expedición. Esta Srta. Acedo, que copiaba en una ocasión el fichero de niños del Grupo Español Defensa de la República, existente en la Casa de España, fue observada y pudo notarse que hacía una doble copia. Al advertirlo, se le recogieron cuantas fichas había extendido en doble ejemplar y se advirtió a Mme. Parkmans que para los fines de la acción pedagógica sobre los niños en la institución que representaba, era suficiente un solo ejemplar de las fichas. Ella hizo constar que tal era el encargo que había conferido a la Srta. Acedo. Al día siguiente se expulsó a ésta cuando se presentó en la Casa de España a seguir copiando las fichas en doble ejemplar. Es lícito pensar - termina irónicamente - si la acción paternal de Su Excelencia sobre los niños de Malinas trataría de llegar mediante la doble lista de la Srta. Acedo a los albergados en Bélgica por otras personas o grupos»..$^{8}$

Fue una frustración más del embajador, ya que, como hemos visto, él había intentado conseguir también las listas católicas, a través de las autoridades civiles, sin lograrlo. Mejores contactos parece que tenía el arzobispo de Malinas ya que, en carta del 29 de diciembre de 1937, el P. Janssens, encargado de las repatriaciones, escribía a mons. Antoniutti

\footnotetext{
${ }^{87}$ «A most surprising point about this list is that even the Home Office, the Catholic Herald understands, does not possess a copy. This means that the Basque Committee is in complete control of the destiny of the children and independently not only of the Catholics and Nationalists, but of the very Government of this Country», en ASV, Arch.Nunz.Madrid 975, Stampe, 545r. El texto es probablemente del Catholic Herald.

${ }^{88}$ AMAE, R-629, 76, f. 41-42.
} 
«Le envío adjunta la lista de niños que están con no católicos. Ha llevado varios días de trabajo, pero confío en que podrá hacer mucho bien. El número final, después del nombre de los niños, es el de la seguridad belga y con él se puede localizar la dirección exacta de los niños». ${ }^{89}$

Como se ve, la «señorita Acedo», claramente una infiltrada, ya que salió de Bélgica hacia la España nacional con la primera expedición de niños repatriados, no era imprescindible para obtener las listas, al menos en Bélgica.

\section{LA NADA DESDEÑABLE CUESTIÓN ECONÓMICA}

En cualquier caso, tener las listas de los contrarios tenía también un evidente valor logístico que ahorraba esfuerzos y, en último término, dinero. Una buena lista permitía localizar padres en España y ver si querían -o presionarlos para - pedir la repatriación. No hay que olvidar que cada día que estaban los niños, incluso - o especialmente- en entornos católicos, costaba dinero. En último término, el agotamiento económico fue el argumento - nada marginal, desde un punto de vista británico- que plantearon los comités ingleses para destacar la conveniencia de las repatriaciones. Ya Álvarez-Buylla, cónsul general en Gran Bretaña, escribía al ministro de Estado el 5 de enero de 1938 alertando ante una posible

«desbandada general de los niños refugiados vascos devueltos por las organizaciones que los atienden, que comienzan a dar muestras de cansancio, acaso porque la tarea que se han echado encima de sus hombros es realmente extraordinaria, y se resienten también de la falta de ayudas económicas»..$^{90}$

De hecho una de las soluciones planteadas fue enviar a los niños a Francia, donde el Gobierno Vasco se haría cargo de los gastos y, eventualmente, devolvería a España a los debidamente reclamados por sus padres: pero da la impresión que ésta era una propuesta en la que lo económico pesaba bastante.

Pero no sólo los ingleses miraban las libras que se iban en atender a los niños españoles. Para Antoniutti, la pronta repatriación sería beneficiosa para todos, sin excluir las arcas de la delegación apostólica, como escribía al card. Van Roey

\footnotetext{
${ }^{89}$ «Je vous envoie ci-inclus la liste des enfants placés chez des non catholiques, elle a demandé plusieurs jours de travail, mais j'espère qu'elle pourra faire beaucoup de bien. Le dernier numéro que se trouve derrière le nom des enfants est celui de la sureté belge. Il vous permettra de retrouver l'adresse exacte des enfants» (ASV, Arch.Nunz.Madrid 976, fasc. 2, 312r).

${ }^{90}$ AMAE, R-895, 48, f. 29.
} 
el 22 de diciembre de 1937 tras indicarle que acababa de entregar 20.000 francos a los sacerdotes que habían llegado acompañando a los primeros repatriados:

«Me permito solicitar a Su Eminencia que la vuelta de los niños reclamados no se demore mucho. Distintas circunstancias lo exigen. Pienso que, incluso desde el punto de vista económico, podríamos ahorrar miles de francos organizando el viaje conjunto de los niños que se encuentran aún en Bélgica». ${ }^{91}$

Y, desde luego, con su colega en Bruselas - colega relativo-, el nuncio Micara habla más claramente, para hacerle comprender - y para que lo hiciese entender a los belgas - que la sangría económica que suponían los gastos de las repatriaciones no podía eternizarse:

«Ha causado una impresión poco favorable el gran retraso con el que se está llevando a cabo la repatriación de los niños vascos de la Obra del cardenal Van Roey que han sido formalmente reclamados por sus padres. Para facilitar su retorno, he entregado, aún en octubre, a mons. Gilbert 200 libras esterlinas, equivalentes a 29,150 francos que hubieran debido bastar para el viaje colectivo de los 450 niños reclamados. Ahora se me dice que esa suma ha llegado sólo para el viaje de los 160 que hasta ahora han sido devueltos a sus familias. He entregado otros veinte mil francos franceses, pero si seguimos a este paso harán falta 90.000 francos para el retorno de los 500 niños que han sido reclamados. No sé si me será posible enviar más dinero para esto; y le agradecería que transmitiese este argumento, nada despreciable, a quien corresponda. Me permito indicar que los niños provenientes de Inglaterra, Francia y Suiza viajan a expensas de los gobiernos o de los comités de las respectivas naciones». ${ }^{92}$

Al parecer, no había sido así en el viaje de ida de los niños, ya que el transporte por tren de Francia a Bélgica había sido cobrado por el gobierno francés y asumido por el belga. ${ }^{93}$

\footnotetext{
${ }^{91} \ll$ Je me permets de demander a Votre Eminence que le retour de tous les enfants réclamés ne soit pas retardé plus longtemps. Plusieurs circonstances l'exigent. Il me semble que, même au point de vue des finances, nous pourrions épargner des milliers de francs organisant le départ collectif des enfants // qui se trouvent encore en Belgique», en ASV, Arch.Nunz.Madrid 976, fasc. 2, 260r-261r.

92 «Ha destato un'impressione poco favorevole il grande ritardo con cui prosegue il rimpatrio dei fanciulli baschi dell'Opera del Card. Van Roey, formalmente richiamati dai loro genitori. Per facilitarne il ritorno, io ho consegnato, ancora in ottobre, a Mgr. Gilbert, 200 sterline, corrispondenti a Fr. 29,150 che avrebbero dovuto bastare pel ritorno collettivo dei 450 fanciulli richiamati. Ora mi si comunica che tale somma ha bastato solo pel viaggio dei 160 finor restituite alle loro famiglie. Ho consegnato altri 20 mila franchi francesi ma se si continua da questo passo ci vorranno novantamila franchi pel ritorno dei 500 richiamati. Io no so si mi sarà possibile inviare altro denaro per questo scopo; e sarai grato a V.E. se volesse far presente questo argomento non trascurabili a chi di dovere. Mi permetto segnalare che i fanciulli provenienti dall'Inghilterra, dalla Francia e dalla Svizzera viaggiano a spese dei Governi o dei Comitati delle rispettive nazioni», en ASV, Arch.Nunz.Madrid 976, fasc. 2, 262r.

${ }^{93}$ ASV, Arch.Nunz.Madrid 976, fasc. 288r-291r.
} 
La presión parece que resultó eficaz - incluso demasiado - ya que en febrero siguiente le enviaron una docena de niños no reclamados, algo que Antoniutti consideró no poco comprometido:

«Al mismo tiempo que le aseguro que me ocuparé con todo empeño de estos pobres niños, considero mi obligación significarle que no puedo asumir ninguna responsabilidad sobre su regreso». ${ }^{94}$

En cualquier caso, bien porque lo pagaban ellos, bien por la ingénita afición británica al ahorro, los datos económicos son más abundantes en Gran Bretaña que en ningún otro país. El Catholic Herald, de 12 de noviembre de 1937, al tiempo que criticaba la repatriación por tren, viaje largo, incómodo y agotador para niños y acompañantes, — «deplorable» ${ }^{95}$ según el reportaje de McGuire, que acompañó a los niños - aprovechaba para hacer un cálculo del precio del viaje y de cómo abaratarlo:

«El Catholic Herald calcula que podría haberse fletado un barco para devolver a los 500 niños a un coste de 2 libras por cabeza (comida incluida). El viaje en tren cuesta 35 chelines por cabeza, pero no incluye las comidas. Hubiera sido mucho mas barato enviar los 500 por mar». ${ }^{96}$

Por otra parte, como también se decía, el envío por tren en pequeños grupos, era una forma de prolongar innecesariamente el exilio. En el fondo, venían a plantear que si los niños habían llegado en grupo y por barco, deberían marcharse igual, ahora que habían cambiado las circunstancias que justificaran su envío a Inglaterra.

\section{NiÑOS ENTRE DOS FUEGOS}

Evidentemente, las notas que aquí recojo de los archivos de Gomá, de Antoniutti o del Ministerio de Asuntos Exteriores español, el franquista y el republicano, pueden multiplicarse y matizarse, ya que la documentación abunda en los ejemplos que he seleccionado. Como ya he dicho, quizá lo que resulta

94 «Tout en assurant V. E. que je m'occuperai avec empressement de ces pauvres enfants, je crois devoir signifier // que je ne peux pas prendre aucune responsabilité pour leur retour», en ASV, Arch. Nunz.Madrid 976, fasc. 2, 324r-v.

${ }^{95}$ ASV, Arch.Nunz.Madrid 975, Stampe, 510r.

${ }^{96}$ The Catholic Herald understands that a ship could have been chartered to take back 500 children at $£ 2$ a head (food inclusive). The train journey is costing $35 \mathrm{~s}$. a head, but this figure does not include food. It would therefore have been cheaper to take the 500 by sea», Catholic Herald, 12.IXI.1937, en ASV, Arch.Nunz.Madrid 975, Stampe, 492r. 
más llamativo, conforme se estudia la batalla por los niños, es la extraordinaria complejidad del problema desde sus distintos ángulos: económico, político, diplomático, jurídico y, sobre todo, humano. Pero al mismo tiempo, esa complejidad se reduce hasta lo elemental si la vemos como un reflejo o una consecuencia de las rígidas fronteras ideológicas de la Europa y la España de la época, fronteras mucho más difíciles de atravesar que las geográficas. Divisiones entre católicos y socialistas (en sentido amplio), entre demócratas (en sentido aún más amplio) y totalitarios, entre Falange e Iglesia en España, entre el gobierno de Euzkadi y el de la República o entre los distintos partidos republicanos. Los niños aparecen coloreados con el tinte del grupo en el que han caído - católicos, republicanos, comunistas, socialistas - y aprenden desde ese grupo el odio al otro que queda completamente descalificado. Valga como ejemplo de esto, y como penoso final, la traducción de la carta que un maestro inglés - profesión y país tolerantes donde los haya - escribía, desde una colonia infantil, a un solicitante de repatriación, carta que un traductor católico se encargó de hacer llegar a la Oficina pontificia de repatriaciones:

«Como quiera que soy maestro en esta colonia de refugiados vascos, Charito me enseñó su carta, concerniente a la así llamada «repatriación», en otras palabras el complot de mandarle así como a otras niñas a un territorio de bandidos. Ella no le echa la culpa a usted por su complicidad en esta conspiración inhumana, considera que Vd. está simplemente llevando a cabo los supuestos deseos de sus abuelos, quienes, naturalmente, están obrando bajo presión.

En esta colonia todos nos hallamos profundamente interesados ahora que el complot ha salido a relucir, y que hasta cierto punto está obteniendo su objeto. Naturalmente Charito está a salvo...

Las vidas de los jóvenes son muy preciosas y tienen que ser protegidas a toda costa. En este tiempo de guerra me parece que tenemos que ejercer sumo cuidado en cuanto a la información que puede llegar a manos del enemigo y las cartas enviadas al territorio rebelde deberían ser vigiladas más minuciosamente.

Supongo que será Vd. católico y espero que Vd. comprenderá que yo respeto su religión, si bien siento que no debiera Vd. cegarse a las manipulaciones de un clero sobornado. Con toda seguridad no es necesario ser anti-católico con el fin de poner a Jesucristo en primer lugar y al Papa después.

Personalmente yo procuro ser cristiano, pero encuentro imposible aplicar la moral cristiana a aquellos que matan niños, con el fin de ser recompensados con mineral de hierro. En una guerra entre personas civilizadas y perros rabiosos, siento que no se puede hacer mas que un cosa, es la de matar a los perros rabiosos». ${ }^{97}$

${ }^{97}$ Es traducción de la carta escrita por «Cyril P. Cule y dirigida a Ramón Selva. 74 Queens Road, Bootle, Liverpool», sin fecha, en ASV, Arch.Nunz.Madrid 977, fasc. 4, 493r. En el encabezado se indica: «Por fin, aunque me lleve algún tiempo, he creído conveniente hacer una traducción de la carta que he recibido del maestro en cuestión». 
Pienso que esta carta refleja bastante bien esa mentalidad excluyente que llevaría a los europeos a recorrer pocos meses después el mismo camino de odio y enfrentamiento que había enviado al exilio a tantos niños españoles.

\section{BiBLIOGRAFÍA}

Alonso Carballés, Jesús et al. 2003. El exilio de los niños. Madrid: Fundación Pablo Iglesias - Fundación Largo Caballero.

Alted Vigil, Alicia. 1999. «Le retour en Espagne des enfants évacués pendant la guerre civile espagnole: la Délégation extraordinaire au rapatriement des mineurs (19381954)», en VV. AA., Enfants de la guerre civile espagnole. Vécus et représentations de la génération née entre 1925 et 1940: 47-59. Paris - Montreal: L’Harmattan.

Andrés-Gallego, José y Pazos, Antón M. 2001-2010. Archivo Gomá. Documentos de la Guerra Civil. Madrid: CSIC. 13 vols.

Arrien, Gregorio. 1988. Niños vascos evacuados en 1937: álbum histórico, [s. 1.].

Bell, Adrian. 1996. Only for three months: the Basque children in exile. Norwich: Mousehold Press.

Bell, Adrian. 2011. Sólo serán tres meses. Los niños vascos refugiados en el exilio. Barcelona: Plataforma.

Buchanan, Tom. 2011. «Las iglesias británicas ante la guerra civil española», en Antón M. Pazos (ed.), Religiones y guerra Civil española: Gran Bretaña, Francia, España: 19-37. Santiago de Compostela: CSIC.

Cárcel Ortí, Vicente. 2006. «Luis Despujol Ricart», en Diccionario de Sacerdotes diocesanos españoles del siglo xx: 380-381. Madrid: BAC.

Cárcel Ortí, Vicente. 2008. Pío XI entre la República y Franco. Angustia del Papa ante la tragedia española. Madrid: BAC.

Clavijo, Julio. 2002. La política sobre la població refugiada durant la Guerra Civil 1936-1939. Girona: Universitat de Girona. Ltd.

Cloud, Y. y Ellis, R. 1937. The Basque Children in England.London: Victor Gollancz

Gabana y Ventura, Enrique. 1939. Mi campaña en Inglaterra. [Barcelona].

García, Hugo. 2008. Mentiras necesarias: La batalla por la opinión británica durante la guerra civil. Madrid: Biblioteca Nueva.

Heers, Jacques. 2006. L'Histoire assassinée. Les pièges de la mémoire. Paris: Éditions de Paris.

Kershner, Howard E. 2011. La labor asistencial de los cuáqueros durante la Guerra Civil española y la posguerra. España y Francia 1936-1941. Madrid: Siddharth Mehta Ediciones 
Kesten, Hermann. 1945. Los niños de Guernica. Novela. Buenos Aires: Futuro.

Legarreta, D. 1984. The Guernica Generation: Basque Refugee Children of the Spanish Civil War. Reno: University of Nevada Press.

Pazos, Antón M. (ed.) 2011. Religiones y guerra Civil española: Gran Bretaña, Francia, España. Santiago de Compostela: CSIC.

Stradling. R. A. 2008. Your Children Will Be Next: Bombing and Propaganda in the Spanish Civil War, 1936-1939. Cardiff: University of Wales Press.

VV.AA. 1999. Enfants de la guerre civile espagnole. Vécus et représentations de la génération née entre 1925 et 1940. Paris - Montreal: L'Harmattan. 